\title{
Respiratory Viral and Bacterial Factors That Influence Early Childhood Asthma
}

\begin{abstract}
Nontobeko Mthembu ${ }^{1+}$, Paul Ikwegbue ${ }^{1 t}$, Frank Brombacher ${ }^{1,2,3}$ and Sabelo Hadebe ${ }^{1 *}$
${ }^{1}$ Division of Immunology, Department of Pathology, Faculty of Health Sciences, University of Cape Town, Cape Town, South Africa, ${ }^{2}$ Division of Immunology, Health Science Faculty, International Centre for Genetic Engineering and Biotechnology (ICGEB) and Institute of Infectious Diseases and Molecular Medicine (IDM), University of Cape Town, Cape Town, South Africa, ${ }^{3}$ Faculty of Health Sciences, Wellcome Centre for Infectious Diseases Research in Africa (CIDRI-Africa), Institute of Infectious Diseases and Molecular Medicine (IDM), University of Cape Town, Cape Town, South Africa
\end{abstract}

Asthma is a chronic respiratory condition characterised by episodes of shortness of breath due to reduced airway flow. The disease is triggered by a hyperreactive immune response to innocuous allergens, leading to hyper inflammation, mucus production, changes in structural cells lining the airways, and airway hyperresponsiveness. Asthma, although present in adults, is considered as a childhood condition, with a total of about 6.2 million children aged 18 and below affected globally. There has been progress in understanding asthma heterogeneity in adults, which has led to better patient stratification and characterisation of multiple asthma endotypes with distinct, but overlapping inflammatory features. The asthma inflammatory profile in children is not well-defined and heterogeneity of the disease is less described. Although many factors such as genetics, food allergies, antibiotic usage, type of birth, and cigarette smoke exposure can influence asthma development particularly in children, respiratory infections are thought to be the major contributing factor in poor lung function and onset of the disease. In this review, we focus on viral and bacterial respiratory infections in the first 10 years of life that could influence development of asthma in children. We also review literature on inflammatory immune heterogeneity in asthmatic children and how this overlaps with early lung development, poor lung function and respiratory infections. Finally, we review animal studies that model early development of asthma and how these studies could inform future therapies and better understanding of this complex disease.

Keywords: T helper 2, bacteria, viruses, asthma, early development, lung function

\section{INTRODUCTION}

Respiratory infections are one of the leading causes of disease morbidity worldwide (1), with infectious agents being the major sources of lung disease mortality (2). Over the last 3 decades, respiratory infections have been reported as the greatest contributing factor to asthma exacerbation in both children and adults. The severity and frequency of exacerbations varies from mild to more serious bronchiolitis, wheezing, or pneumonia in the lower respiratory airway (3). What is puzzling in newborns who develop these symptoms is that the acquired maternal antibodies meant to protect at this early age, do not seem to function optimally leading to significant morbidity and mortality. In 2010, 5 million deaths were reported in children below the age of 5 years, of which $64 \%$ were due to infectious agents within 30 days of life (4). 
Allergic asthma is a common and major childhood illness that is caused by a combination of several factors including genetics and environmental factors such as microbes, air pollutants, aeroallergens, food, and many other factors yet to be determined (5). This complex chronic lung disease is characterised by shortness of breath, coughing, bronchospasm, and wheezing sound, caused by pathophysiology of obstructed airway and hyperresponsiveness (6). The disease affects over 300 million people worldwide and in 2019 an estimate of 461,000 related deaths were reported according to WHO (7). In the USA, $\sim 10 \%$ of school-aged children are affected by asthma with at least $95 \%$ of those children having developed the disease before the age of 5 years (8). Several infectious agents have been associated with increased burden of asthma and wheezing in newborns, including bacterial, fungal, and viral infections $(9,10)$. Viral respiratory infections are considered as the single greatest cause of mortality and economic burden (11). In the USA, conservative estimates of economic costs of viral infections was $\sim$ \$25 billion per annum with the highest impact observed in young children (11). Apart from viruses, bacterial infections have also been associated with significant asthma burden, accounting for many wheezing illnesses that may lead to early childhood asthma (8).

Despite substantial progress made in the past two decades to better understand risk factors, environmental triggers, phenotypes, and pathophysiology of the disease, key disease determinants, exacerbation factors, and prevention strategies remain elusive. In genetically predisposed individuals, respiratory viral and bacterial infections have emerged as a major predictive factor in developing wheezing at an early age (12). The detection rates of these infectious agents are highest among infants with wheezing and recurrent illnesses compared to adult's counterpart with wheezing signs (9). Among viruses detected, human rhinovirus (RV), respiratory syncytial virus (RSV), enteroviruses, human bocavirus, influenza viruses, human parainfluenza viruses, and coronaviruses have all been associated with asthma exacerbations in humans (13). Rhinoviruses are a more common single trigger of acute asthma exacerbations in school-age children, accounting for up to $76 \%$ of wheezing episodes in this age group (9). On the other hand, RSV is recognised as a second most common respiratory virus connected to wheezing sound and subsequent development of asthma in the first few months of life $(3,14)$. Bacterial species that have been linked with asthma exacerbations include Haemophilus influenza, Streptococcus pneumoniae, Moraxella catarrhalis, Mycoplasma pneumoniae, Chlamydia pneumoniae (15).

Asthma is a disease that has always been characterised by the presence of T helper 2 (TH2) airway immune cells such as eosinophils and allergen-specific IgE production by plasma cells (16). More recent studies using in depth molecular techniques and immune profiling in the airways or bronchoalveolar lavage (BAL) fluid have shown a far more complex disease with distinct but overlapping endotypes $(6,17)$. These endotypes represent TH2 high, TH2 low, TH1 and TH17 types or mixed phenotype often associated with asthma severity and non-responsiveness to corticosteroids (discussed in later sections) $(17,18)$.
During childhood (when the immune system is not fully mature), recurrent respiratory infections may induce impairment on the developing lung and alter its function through disruption of epithelial barrier integrity (Figure 1) (19). This could have long-term imprint in the lung and subsequent development of early childhood and late onset asthma (19). These epigenetic modifications and rapid hypomethylation of regulatory regions of $\mathrm{TH} 2$ genes at an early age suggests that early interventions during development in predisposed individuals may be beneficial therapeutically (20). Early immune education of the immature immune profile in the developing lung may serve as a critical window to prevent wheezing and asthma, however these studies are difficult to conduct in humans. Animal studies have shed light on how early respiratory infections can influence development of asthma at an early age. For instance, respiratory viral infected mice responding to aeroallergens sensitisation demonstrated increased and chronic airway responsiveness and inflammation (21). These observation suggests that viral induced infections in infancy may increase the risk and severity of asthma development at later stages of life (Figure 1). Whether this interaction is a direct effect of viral or/and bacterial replication in respiratory epithelial tissues or indirect effects emanating from certain secondary underlying conditions or factors that predispose individuals to atopy is still not clearly defined (22).

Clinical evidence from human studies and mouse studies supports a hypothesis that utero and postnatal inflammatory profile is TH2 biassed which may be the bases for development of asthma disease in children $(23,24)$. Respiratory viral and bacterial infection have been reported to promote early wheezing and later development of asthma with long term impacts on lung function. In this review, we focus on different respiratory viral and bacterial pathogens and their association with asthma exacerbation in children under the age of 10 years. We emphasise how inflammatory immune heterogeneity in asthmatic children overlaps with respiratory infections and poor lung function. We further highlight how animal studies could be a holy grail in uncovering early development of this heterogeneous and complex disease.

\section{IMMUNOPATHOPHYSIOLOGY OF ASTHMA}

Asthma is characterised by shortness of breath and wheezing due to reduced air flow in terminal and smaller bronchial airways of the lung (25). The pathology of the disease is characterised by increased influx of granulocytes such as eosinophils, TH2 cells, increased circulating immunoglobulin $\mathrm{E}$ and mucus hypersecretion in the airways $(26,27)$. These symptoms are, in most cases, reversible upon bronchodilator or corticosteroid administration. However, over 5 decades ago Schwartz and colleagues first reported a phenomenon whereby this treatment was ineffective which they described as a "decrease in eosinopenic response to Cortisol and an accelerated plasma Cortisol clearance" (28). Since then, more studies have come out exploring steroid resistant asthma citing disease severity as a common feature among this sub population of asthmatics (2931). A patient is considered to have steroid resistant asthma 


\section{Human lung Development}

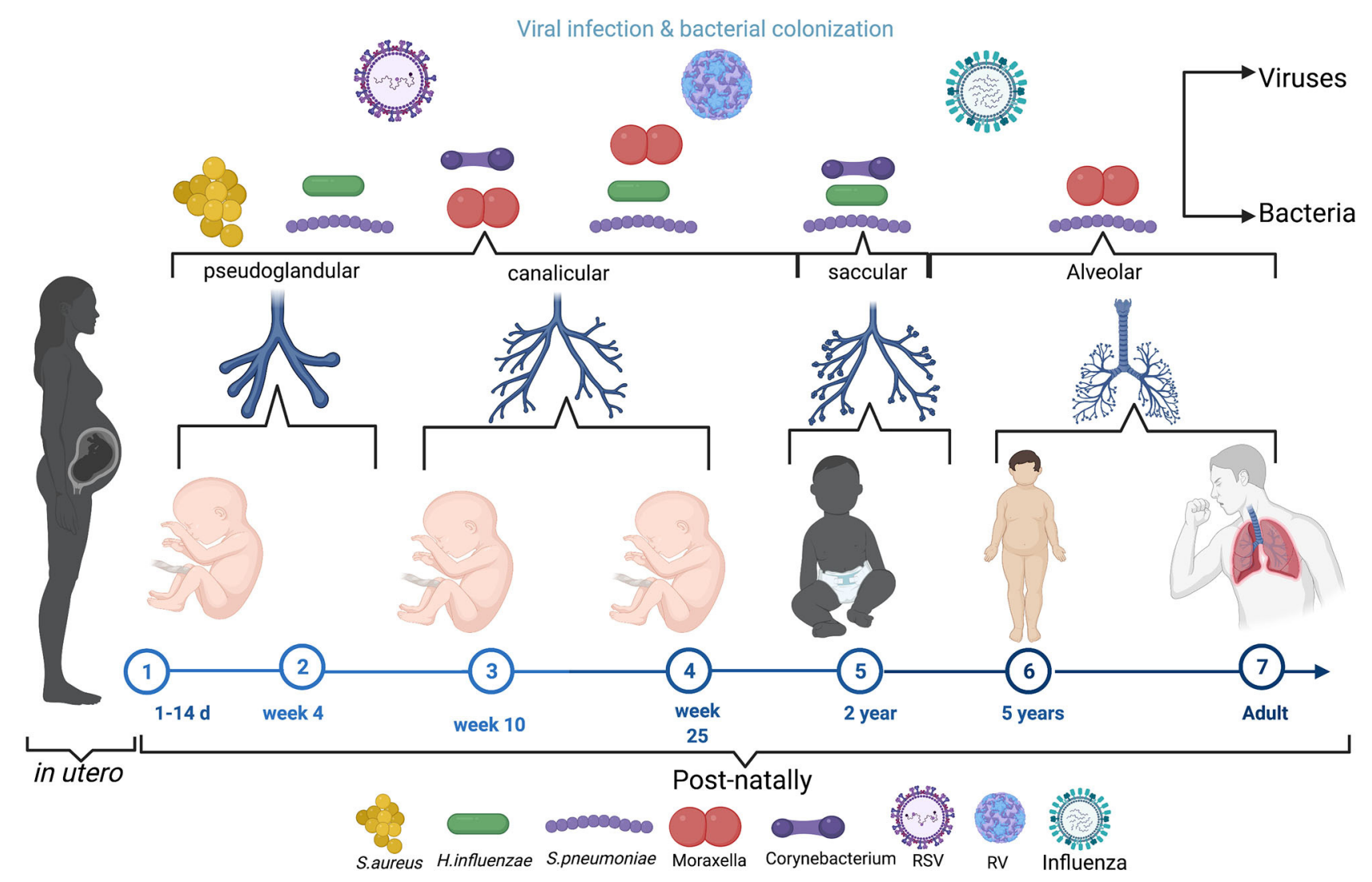

FIGURE 1 | The diagram elaborating the neonatal exposure to viral and bacterial infections during the crucial stage of lung development. During pseudoglandular and canalicular of lung development (Day 1-25 week) where lung are thought to be more susceptible to early-life pathogens like Respiratory syncytial virus, S. aureus. From 25 week to 2 years (saccular), the most reported microbes in this age are RV, $H$. influenza, S. pneumonae, Moraxella, Corynebaterium, and then influenza virus can infect at time from birth to school age and adult. Created with BioRender.com.

when the amount of air exhaled during forced expiratory volume per second $\left(\mathrm{FEV}_{1}\right)$ cannot be rescued by $15 \%$ from baseline after steroid treatment over a period of 2 weeks $(32,33)$. Further investigations have also shown that these patients are characterised by a remarkably low eosinophilia and a prominent neutrophilic response $(34,35)$. Therefore, while asthmatics may present with similar symptoms, evidently the pathophysiology behind these similar clinical and physical presentation varies. The discovery of a non-eosinophilic type of asthma led to a change in paradigm in how asthma was being diagnosed and treated and resulted in further characterisation of the disease into multiple endotypes based on inflammatory granulocytes present and cytokines accompanying this inflammation $(6,35,36)$.

\section{IMMUNE PROFILE IN ASTHMATIC CHILDREN}

Asthma is a heterogeneous disease common in both children and adults and present with multiple and variable inflammatory states. In more recent years there has been a renewed interest to characterise these heterogeneous immune inflammatory phenotypes in order to identify appropriate and personalised therapeutics for each disease phenotype. In adult asthma, the disease has largely been characterised as either mild/moderate or severe form (37). Mild and moderate forms of asthma are associated with eosinophilic inflammatory cells in the BAL fluid or sputum and TH2 cytokines (IL-4, IL-5, and IL-13) with increased serum IgE (25). Beside TH2 cells, group 2 innate lymphoid cells (ILC2s) play a crucial role in mediating the type 2 immune response through production of IL-5 and IL13 when activated by alarmins IL-25, IL-33 and thymic stromal lymphopoietin (TSLP) in response to epithelial cells damage induced by viral infections or allergens (Figure 2) (38). Severe forms of asthma have been associated with mixed granulocytes or neutrophilic inflammation accompanied by T helper 17 (TH17) cells and its associated cytokines [IL-17A, IL-6, granulocyte colony stimulating factor (G-CSF), tumour necrosis factor $\alpha$ (TNF- $\alpha$ ), and C-X-C motif ligand 8 (CXCL8)] (39). TH2 high endotype has been observed with much higher airway nitric oxide, airway and peripheral blood eosinophils compared to 


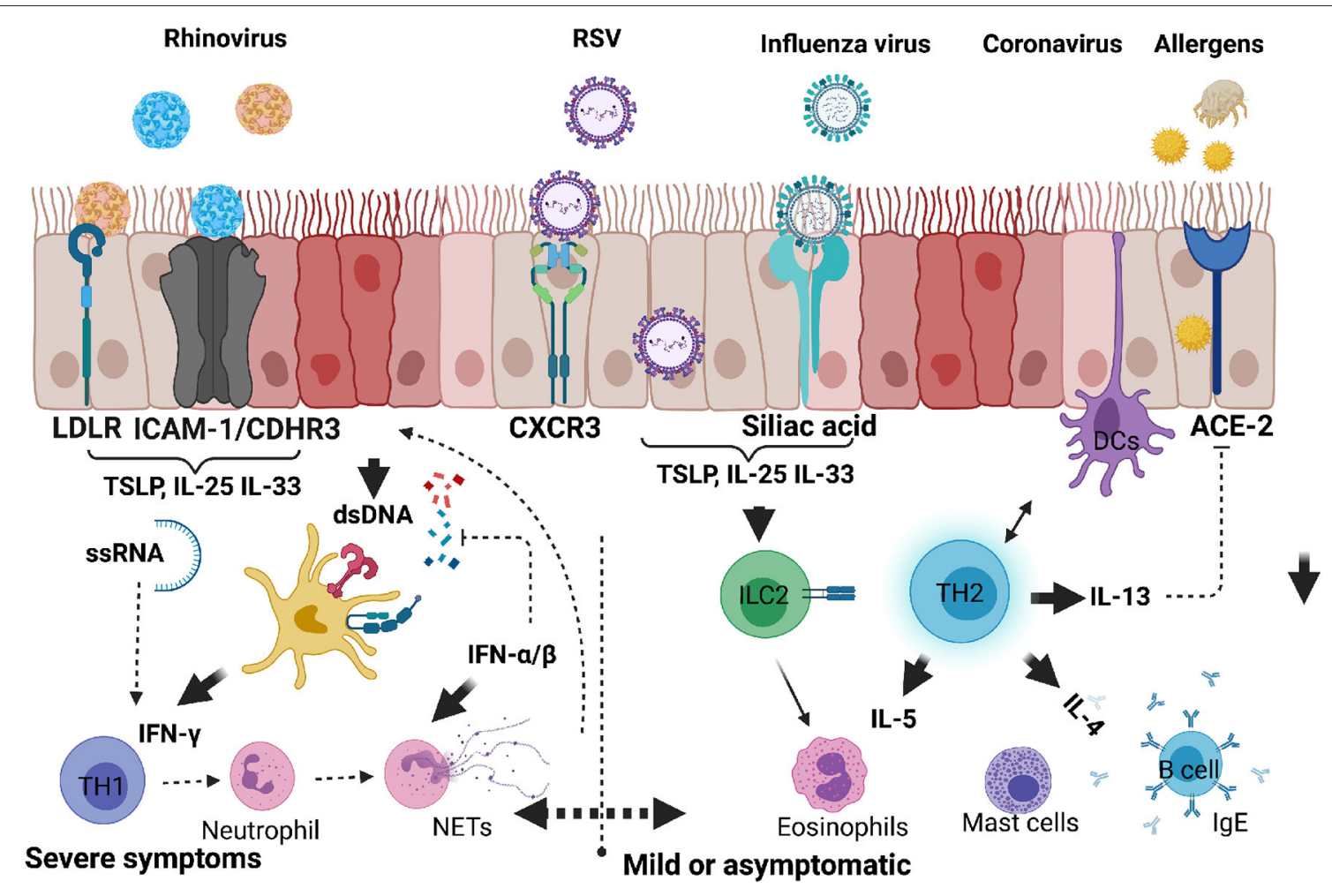

FIGURE 2 | Respiratory viruses that infect upper and lower respiratory airways causing inflammatory response and exacerbating allergic asthma in children. When infectious agents such as viruses or allergens bind to their respective receptors on the surface of epithelial cells, they activate downstream signals. Upon these agents entering in asthma predisposed individuals, there is an increased tendency to produce proinflammatory cytokines such as IL-25, IL-33, or TSLP by epithelial cells. ILC2 are directly activated to produce IL-5 and IL-13, whereas TH2 cells are activated by DCs. Viral RNA or DNA can be detected by host nucleic acid receptors which help produce IFN- $\alpha / \beta$ and promote anti-viral TH1 cells producing IFN- $\gamma$. Dysregulated antiviral response can lead to neutrophil degranulation, NETosis and exacerbation of mild or moderate responses to severe form of allergic asthma. Created with BioRender.com.

TH2 low endotype (17). TH2 high endotype groups have a high IL-13 transcriptional signature in lung epithelia and periostin in blood (37). These group of patients also tend to be more responsive to corticosteroids, although there are subgroups of a considerable size that have been reported to require high doses of corticosteroids to control asthma (37). More recent studies in adult asthma has shown a non-redundant role for $\mathrm{T}$ helper 1 (TH1) cells and its associated cytokine IFN- $\gamma$, and chemokines, CXCL10, MIP-1A (40). In this setting TH1 cells were associated with severe forms of asthma, contrary to the long-held notion that these cells counter and protect against developing asthma (Figures 2, 3).

In children, heterogeneity of asthma is less explored partly due to difficulties in obtaining bronchoscopy procedures at that age and limited ability of children to induce sputum. Children are often on high dose inhalable or oral corticosteroids which dramatically change the immune inflammatory profile in the lung $(41,42)$. In a few studies that have looked at heterogeneity of the asthma inflammatory profile in children, 4 distinct categories could be identified, and these included an eosinophilic type, mixed granulocytic infiltrate, and neutrophilic type (42, 43). Children with the neutrophilic type of asthma were generally found to be younger (between 3 and 9 years old). The neutrophil infiltrate coincided with detection of viral and bacterial pathogens, mainly rhinovirus and Haemophilus influenza A, respectively (43). Neutrophil inflammatory phenotype was far more heterogenous and further divided into sub-groups, but generally associated with steroid-refractory type of asthma. Neutrophilia in the BAL fluid of children was associated with increased CXCL8, CXCL10, G-CSF, and IL-17. Interestingly, CXCL8, the highest predictor of neutrophilic inflammation was not associated with presence of viral or bacterial pathogens, suggesting that respiratory infection may not be a main driver of this chemokine response and that infection and cytokines may drive neutrophilic asthma independently (43). In another study, neutrophils were found to be increased in children with severe therapy refractory asthma (STRA), which correlated with increased IL- 8 production by primary bronchial epithelial cells from the same children $(44,45)$. Interestingly, intraepithelial neutrophils but not overall BAL neutrophils were associated with improved lung function (44). IL-17A was found to act indirectly in promoting intraepithelial neutrophil influx, by stimulating increased expression of its receptor IL-17RA in epithelial cells which in turn released more IL-8 to chemo-attract neutrophils. This particular study in children paints a very complex and contradictory picture of $\mathrm{TH} 17$ cells in neutrophilic asthma, 


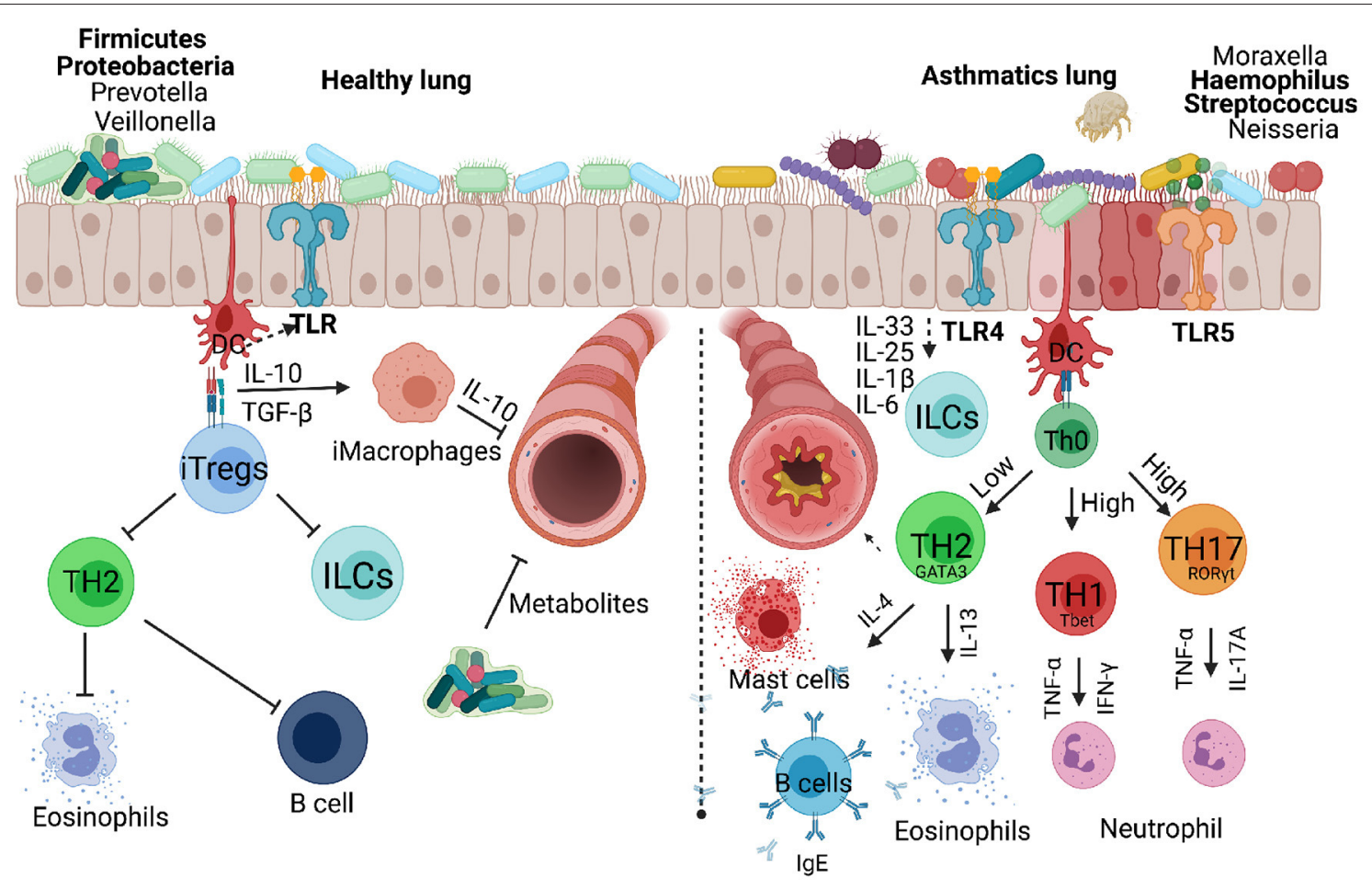

FIGURE 3 | Respiratory bacteria and microbiota that infect or reside in the upper and lower respiratory airways either inhibiting or exacerbating development of allergic asthma in children. Microbiota dominated by Firmicutes and Proteobacteria protect a developing lung promoting secretion of metabolites that can inhibit infectious microbes. Inducible regulatory cells play a key role in countering TH2, innate lymphoid cells and B cells which contribute to asthma development. Invading microbes can either counter TH2 responses or exacerbate allergic asthma through activating TLRs signals that favour TH1 or TH17 responses associated with severe form of asthma. Created with BioRender.com.

different to what is observed in adults. T helper 1 cells have been shown to be present in both non-allergic and allergic children with severe asthma (46). These cells were found within the TH2 milieu and dominated in BAL fluid rather than blood, secreting signature cytokines IFN- $\gamma$ and CCR5 and positively correlated with common allergen-specific IgE secretion. The nature of their development and maintenance in such an environment is unclear, but it is thought that plasmacytoid dendritic cells secreting type I interferons may be the main driver of these cells (Figure 2). Other cell types that have been found to be associated with steroid refractory asthma in children are ILC2s. These cells are sparse, express ST2 and are thought to be the main producers of IL-13. More recent studies showed ILC2 to be associated with steroid resistance in children and are sensitive only to systemic corticosteroids (47-49). CD45RO expression by inflammatory ILC2 has been linked to acquisition of steroid resistance in asthmatics $(50)$.

\section{POOR LUNG FUNCTION AT EARLY AGE AND THE DEVELOPMENT OF ASTHMA IN CHILDREN}

The period of 0-6 years is crucial, as it is during this phase that the majority of asthma cases are reported $(51,52)$. Poor lung function at infancy has been identified as one of the predisposing factors of childhood-onset asthma $(53,54)$. Wheezing in the first year of life is a key feature of impaired lung function resulting from respiratory infections which are recurrent during childhood (Figure 1). In a longitudinal study by Martinez et al. (55) where they followed up children from birth till the age of 6 years, they reported that almost half of the children enrolled in the study had recurrent wheezing episodes by the time they reached age 6. They also presented with signs of diminished lung function (55). They further noted respiratory infection in lower airways by the age of 3 as the leading cause of wheezing which they associated with asthma predisposition. Over two decades later, a follow up study led by Tai et al. (56) further reported wheezing at infancy as a risk factor for subsequent asthma development in adults who were followed up for 50 years (56). Considering that asthma in adolescence is linked to wheezing during the first 6 years of life and subsequent defective lung function, it is therefore within reason to infer that poor lung function in early life does not only predispose children to asthma development, but may be the reason behind disease severity in adults $(56,57)$.

Several risk factors have been associated with poor lung function in children which leads to poor quality of life. These include maternal smoking, preterm birth, birth weight, heavy use of broad antibiotics at an early age, air pollution $\mathrm{PM}_{10}$, respiratory infections and in some parts of the world human 
immunodeficiency virus (HIV) exposure in utero (58). The mechanisms of how these environmental factors influence lung function are unclear. There has been some suggestions that thickening of the reticular basement membrane of the airway smooth muscle in adolescence may be linked to early functional changes that happen in the first few years of life (59). In a study by Altman et al. (60) using RNA sequencing in nasal and blood samples from children with poor lung function, 2 modules were related to asthma exacerbations and these included SMAD-3 network cluster which is related to epithelial differentiation. This network also included genes involved in wound healing and epithelial differentiation such as transforming growth factor beta (TGF- $\beta$ ), KLF4 and FZD1. These studies have been further validated in animal models, where mice lacking TGF- $\beta$ in epithelial cells fail to induce AHR and ILC2 activation $(61,62)$. Other modules associated with asthma exacerbations in children included extracellular matrix (ECM), which was mainly dominated by genes such as iNOS, collagen associated genes COL1A1, CAV1, CFTR, and EPHA1 (60).

In this group of children with exacerbations of asthma, they also found an eosinophil activation/mucus hypersecretion module, which was mainly dominated by genes associated with mucus production, MUC5AC, the respiratory proliferator marker KRT8 and genes associated with eosinophil surface marker and activation, CD9 (60). There were also genes associated with eosinophil identity, IKZF2 and also genes associated with epithelial mesenchymal communication in asthma such as FGFR2. Interestingly, some of these genes (IKZF3, PGAP3, GSDMA, GSDMB, ERBB2, and ORMDL3) fall within 17q21 locus which is linked with high risk of children developing early wheezing episodes due to viral and fungal exposure (63). The subsequent study that focused on ORMDL3 proposed that its mechanism is related to the regulation of ICAM1 and epithelial response to stress due to detection of unfolded proteins, which could explain higher vulnerability toward RV infections and an important mediator of AHR induced by fungal allergens (64). Asthma is a heritable disease and host genetics play a crucial part in susceptibility to the disease, for more detailed reviews on this topic we refer the reader to this review article (9).

\section{ASTHMA RELATED INFECTION}

\section{Association Between Viral Infections and Early Childhood Asthma}

The association between viral infections and early childhood asthma is an area of research interest, and advances in virus detection methods such as more sensitive polymerase chain reaction (PCR) have propelled early detection of different viral genotypes (65). Host genetics and other external environmental agents have been associated with asthma exacerbation in young children. Viral infections are thought to be the major triggers of asthma exacerbation, accounting for $80-95 \%$ in children compared with $75-80 \%$ in adults (66). Respiratory viral infections are important causative agents of many lower tract respiratory illnesses in early childhood ranging from wheezing episodes to more severe bronchiolitis which could lead to later development of asthma (67). Respiratory syncytial virus and rhinovirus are the most common and frequently detected viral exacerbation in newborns (68). Initially, RSV was thought to be a major etiologic agent of viral induced exacerbation, however, subsequent studies have shown that RV dominates after 12 months of life (Figure 1) (13). Thus, this suggests that RSV is the major cause of exacerbation in the first year of life after which RV takes over (9).

\section{Respiratory Syncytial Virus}

Respiratory syncytial virus is a lipid-enveloped negative-stranded RNA virus, which belongs to the Paramyxoviridae family. It is known to cause the majority of respiratory infections in children under the age of 1 year (69). There are two major antigenic groups of RSV, A and B, with about 10 antigenic A genotypes and 13 antigenic $B$ genotypes (70). The severity of RSV infection varies, with most children experiencing relatively mild infection and only $2-3 \%$ requiring hospitalisation (71). Children that are particularly at higher risk are those born prematurely, with immunodeficiency, with neuromuscular disorders or those with chronic lung or congenital heart diseases $(70,72)$. The attachment protein $(\mathrm{G})$ and the fusion protein $(\mathrm{F})$ are the two main surface glycoproteins which play a significant role in the pathogenesis and infectivity of RSV, making them the main targets for the host humoral immune defence (73). Humanised monoclonal antibodies directed against $\mathrm{F}$ glycoprotein can decrease the risk of hospitalisation due to RSV infection in preterm infants (74). These findings formed the basis for potential vaccines or antiviral drugs currently in clinical development.

RSVs bind to CXCR3 on the surface of respiratory mucosal cells through their surface proteins ( $G$ and $F$ ) which initiates attachment and fusion of viral envelope with the host cytoplasmic membrane leading to internalisation (75) (Figure 2). RSV products such as ssRNA and protein are detected by both nucleic and protein pattern recognition receptors which initiate signals leading to transcriptional factor activation and type 1 and III secretion (76). The ability of RSV to penetrate smaller airways allows it to spread to deeper parts of the lung where they can replicate in type 1 pneumocytes $(70,73)$. It is the combined effects of hyper immune activation by innate cytokines and viral replication in many parts of the lung that lead to apoptosis of epithelial cells, sloughing and mucus hypersecretion airway obstruction and wheezing (77).

\section{Rhinovirus}

Rhinovirus is a small sized positive non-enveloped strand RNA virus, which belongs to the Picornaviridae family (78). It is broadly classified into three major serotypes according to its capsid binding receptors and genomic sequences, namely: RV-A, $\mathrm{RV}-\mathrm{B}$, and more recently discovered RV-C (78). There are over 80 RV-A serotypes, 32 RV-B serotypes and 65 RV-C serotypes. RV-A and RV-C are the most likely cause of severe wheezing and asthma exacerbation in children (79). Improved techniques have allowed for easy detection of several RV serotypes, however, structural and genetic variability across all RV serotypes has hampered efforts to develop effective vaccines or antiviral drugs 
against them (70). Both drugs aimed at capsid protein or 3C protease inhibitors are not effective against all serotypes (70). Effective future drugs and vaccines are likely to target crossreactive antigens and possibly multiple antigens.

RV normally causes the common cold in children with up to $35 \%$ asymptomatic individuals testing positive for RV (80). $\mathrm{RV}$ does not induce chronic infections in healthy individuals, although systemic immune responses have been observed in children presenting with wheezing (80). In adult human challenge studies with RV, asthmatics were found to have increased exacerbations shown by increased type 2 inflammation (Figure 2). Mechanistically RV induced release of host dsDNA and damaging NETosis causes lung tissue damage and airway hyperreactivity (Figure 2) (81). These mechanisms, although not tested in children are likely to be the main contributing factors in early wheezing.

Upon RVs entering the host they bind to mucosal epithelial receptors with RV-A preferentially binding to intracellular adhesion molecule 1 (ICAM-1), RV-B to low density lipoprotein receptor (LDL-R), and RV-C binding to cadherin-related family member-3 (CDHR3) (70). CDHR3 is a risk factor for asthma and its polymorphisms particularly rs6967330 are associated with acute severe exacerbations in children (82). Binding of the viral capsid to these innate receptors such as TLR4 leads to activation of innate alarmins such as those seen during allergic asthma such as IL-25, IL-33, and thymic stromal lymphopoietin (TSLP) (Figure 2). The release of these cytokines initiate a cascade of inflammatory cells which leads to epithelial permeability, loss of epithelial barrier integrity, release of host DNA and further entry of viral proteins (76, 83). It is the combination of these pro-type 2 environment and enhanced absorption of other allergens and pathogens that lead to impaired lung function, airway obstruction and airway hyperresponsiveness $(76,83)$.

\section{Influenza Viruses}

Influenza viruses are envelope medium-sized negative sense RNA viruses with eight segmented genomes belonging to the Orthomyxoviridae family (84). There are four groups of influenza viruses: influenza A, B, C, and D. All the four strains have been reported to infect and cause diseases, IAV is the major and common pathogenic strain in humans (85). Morphologically, these viruses are spherical to ovoid-shaped which contain two major surface glycoproteins hemagglutinin (HA) and neuramidase (NA) at 4:1 ratio (86). There are about 16 subtypes of $\mathrm{HA}(\mathrm{H} 1-\mathrm{H} 16)$ and 9 subtypes of NA (N1-N9) discovered so far, and among all these strains, only H1N1 and H3N2 are known to infect humans and cause seasonal influenza (87). At least 4 IAV pandemics that claimed over 50 million lives have been documented worldwide since the first H1N1 outbreak in 1918, followed by H2N2 in 1957 and H3N2 in 1968 (88). A more recent outbreak happened in 2009 due to H1N1 which killed an estimated 280,000 $(157,700-575,400)$ people worldwide according to Centre for Disease Control.

Influenza viruses remain one of the leading causes of severe pneumonia or bronchitis early childhood, despite universal availability of influenza vaccines that prevent infections in under 5 years (89). Direct evidence both experimentally and epidemiologically have failed to show clear associations between influenza viral infection and asthma exacerbation in early childhood due to the inconsistencies and contradictory results in animal models or laboratory experiments (90).

Influenza A virus enters the lung and binds to sialic acid on the surface of alveolar epithelial cells through its HA component, which triggers the endocytosis of the virion into the host cell (Figure 2) (91). After viral replication in the nucleus, viral assembling, budding and scission take place at lipid raft in the plasma membrane (92). The newly formed virion binds sialic acid receptors, and later cleaved by NA component of IAV to release the viral progeny that can infect other cells (93). The viral replication that hijack eukaryotic machinery induces both innate and adaptive immune responses, which triggers the release of several immune cytokines including IFNs, TGF- $\beta$, IL-10, and IL-13, to mount an anti-viral response that is beneficial to the host (88). However, the prolonged presence of these cytokines in the lungs, especially IL-13, have been associated with asthma exacerbation (94).

\section{Coronavirus}

Coronavirus disease 19 (COVID-19) is caused by severe acute respiratory syndrome coronavirus-2 (SARS-CoV-2), which belongs to the family of Coronaviridae and order of Nidovirales. SARS-CoV-2 is the latest discovered member of the coronavirus family which preferentially affects respiratory tract (nose and lungs), leading to common cold, bronchitis, and pneumonia (95). Since the first reported paediatric case of a 10 year old boy in Wuhan, a multitude of coronavirus cases have been reported globally in young children (96).

Initially, there was a growing concern of childhood asthma being a risk factor for severe COVID-19 outcomes. Subsequent studies, however, have not supported this view arguing that paediatric asthma could rather protect against COVID-19 (97). This is due to the presence of TH2 cytokines and frequent use of inhaled corticosteroids (ICSs), which suppress angiotensin converting enzyme 2 (ACE-2) $(98,99)$. SARS-CoV-2 enters the human host through the nose and travels to alveoli in the lower respiratory tract, where it attaches to ACE-2 receptors on type I and II alveolar cells through proteolytic activity of transmembrane protease serine 2 (TMPRSS2) (Figure 2) (100, 101). SARS-CoV-2 once bound to ACE-2 receptor triggers a cascade of proinflammatory cytokines such as IL-6 which have been associated with exuberant immune responses leading to cytokine storm and severe disease outcomes in the elderly (102).

Childhood asthma has been shown not to be a risk factor for COVID-19 disease complications. These could be attributable to (1) cross-immunity from other similar coronaviruses; (2) lower risk of non-communicable diseases such as cardiovascular diseases, (3) low expression of ACE-2 receptors and TMPRSS2 in both nasal and airway epithelial cells (100): and (4) and lastly, type 2 cytokines such as IL-13 and use of corticosteroids 
which are thought to suppress ACE-2 receptor expression via downregulation of type I interferon (Figure 2) $(103,104)$.

\section{Human Immunodeficiency Virus}

Despite significant progress made in reducing mother-to-child human immunodeficiency virus (HIV) transmission in SubSaharan Africa, where almost 30\% of pregnant women are living with HIV (105), there remains a huge burden of HIV-exposed uninfected (HEU) infants. These HEU children are in great danger of developing respiratory infections, as well as a high chance of morbidity and mortality due to invasive pneumonia and respiratory syncytial virus (RSV) in early life (106-109). There are several risk factors associated with prevalence and mortality in HEU children including, pre-term birth, low birth weight, low maternal CD4 count, bacterial meningitis and severe pneumonia $(110,111)$. Perinatal exposure to anti-retroviral therapy (ART) has been associated with abnormal mitochondrial morphology and subclinical defects in hematologic parameters in HEU children, which may persist throughout childhood $(112,113)$. In addition, it has been hypothesised that poor lung growth and functions via dysregulation of metabolic pathways in HEU are linked to maternal antiretroviral therapy (114). However, initiation of ART prior to pregnancy has shown to improve maternal health, as well as reduce the risk of respiratory infections, morbidity and hospitalisation in these children in the developed countries (115). What seems to be the main contributing factor in HEU is immune defects in both humoral and cellular responses which may be the main contributor to respiratory infections and poor lung function. Compared to HIV unexposed uninfected children, HEU demonstrated lower antibodies to several pathogens, which could potentially increase early life susceptibility to infectious agents (116). HEU infants also show increased lymphocyte phenotypes which leads to deficiency in the production of TH1 cytokine, IFN- $\gamma$, which limits activation of antigen presenting cells (APCs) $(117,118)$. This deficiency in TH1 cells has been shown to lead to pneumonia caused by Pneumocystis jirovecii in the first 6 months of life in at least a 3rd of HEU infants (118).

Whether HEU is a risk factor for asthma is currently unclear, but what seems to be common is poor lung function and susceptibility to infections in the first 6 months. One example is RSV infection which resulted in prolonged hospitalisation and deaths in HEU children (107). RSV is also the major inducer of asthma exacerbation in young children, future studies should investigate the link if any, between HEU and asthma exacerbation in the first few months of life.

\section{MICROBIAL COMPONENTS AND ASTHMA}

The bacterial cell wall is composed of various components, each with a contributory role in protecting and keeping the bacteria's structural integrity. Gramme-negative bacteria bear, among other molecules, endotoxins, which are crucial to the cell's survival and function (119). Endotoxins are lipopolysaccharides (LPS) ubiquitous in both the outdoor and indoor environment, with the main source of these molecules being livestock, pets, etc. $(119,120)$. Despite their toxic propensity, the beneficial influence that these molecules have as therapeutic intervention for various conditions has been widely demonstrated $(120,121)$. In asthma, specifically, a beneficial role has been noted in several studies where endotoxins derived from farm animals have been associated with a decrease in asthma development in children (122125). In Germany, one of the large studies that enrolled 10,163 children of school going age (5-7 years) observed an inverse relationship between the development of allergic diseases, including asthma and animal exposure (123). In this study they showed that the repression of atopic disease manifestation was a consequence of bacterial-derived molecules attributable to consistent and augmented animal exposure, which is inherent for children who grow up in farms. This substantiates the hygiene hypothesis which states that increased infections or dirty environments in early-life lead to reduced autoimmune and allergic disorders (126). The hygiene hypothesis is, however, a controversial subject, with various studies arguing for and against it (127-131).

Despite the apparent instrumental role of endotoxins against atopy, as evidenced by the above-mentioned studies, literature has also established the negative effect these molecules possess. Endotoxins are important immune response inducers, as such, they have been implicated in the development of allergic diseases including asthma $(119,132,133)$. Upon inhalation endotoxins are recognised by PRRs such as Toll-like receptor 4 (TLR4). The lipid A portion of endotoxins drives the ensuing immune response by triggering a proinflammatory response characterised by cytokine production and cellular responses $(134,135)$. In 1989 a study evaluating lung function following endotoxin exposure revealed a decrease in carbon monoxide diffusion, increased bronchial reactivity and a slight decrease in $\mathrm{FEV}_{1}$ (136), which are all key features of asthma. However, it has been suggested that responses observed following endotoxin exposure are dose dependent, with a low dose conferring protection to infections and a high dose capable of eliciting a detrimental response such as septic shock (Figure 3) (136-138). It is therefore clear that the interaction between genetics and environmental factors plays an influential role on the outcomes of allergic responses.

Another ubiquitous bacterial component is flagellin which is a protein, not unique to, but mostly present in Grammenegative bacteria. Besides its incorporation as an adjuvant in vaccine design, this protein has proinflammatory abilities as it is recognised by the innate receptor TLR5, expressed on the surface of innate immune cells (139). In comparison to LPS, another potent immune inducer, it has been found to be superior as a mucosal immune cell activator (140142). Similar to LPS, studies have shown conflicting evidence on the role of flagellin in allergic diseases including asthma (Figure 3). While some authors have raised the importance of this protein in the suppression of allergic response by supporting a more regulatory response, others have associated this very same molecule with inflammatory responses that trigger asthma. For example, in an asthma mouse model it has been demonstrated that a higher dose of flagellin exposure confers 
protection against asthma development through the induction of immunoregulatory $\mathrm{T}$ cells and dendritic cells ( $\mathrm{rDCs}$ ) via the TLR5 pathway (143). This inhibitory effect of flagellin on asthma was accompanied by reduced AHR and airway inflammation. The effect of flagellin or its receptor, TLR5, on early-onset asthma remains elusive in humans, specifically in children, with only one study on atopic dermatitis during infancy correlating reduced risk of atopic dermatitis development to increased expression of TLR5 in cord blood (144). Considering that TLR5 level of expression inversely correlates to atopic dermatitis, and developing atopic dermatitis at infancy partially predisposes individuals to childhood asthma (145), it is therefore fitting to propose that TLR5 stimulation at early life stages serves a protective role to asthma development (Figure 1). However, a contradictory role of flagellin was first reported by Wilson and colleagues in 2012 who, using a mouse model found flagellin exposure detrimental as it drove a $\mathrm{TH} 2$ biassed response which in turn promoted asthma manifestation in mice (146). Furthermore, they detected high levels of flagellin-specific antibodies in asthmatic patients suggesting that exposure to flagellin could be a risk factor for asthma.

It is clear that the role of microbial components and their associated receptors in asthma development is contradictory and strongly influenced by the experimental setting including dose and timing. A very important question remains, what does this mean for humans? The concentration of allergens to which humans are exposed to cannot be controlled nor can the age at which this exposure occurs.

\section{BACTERIAL INFECTION AND ASTHMA}

Bacterial respiratory infection at early childhood is closely associated with asthma development. While most studies have referenced viruses such as rhinovirus and respiratory syncytial virus as important inducers of asthma in early life, we now know that bacterial colonisation also drives disease exacerbation (147). Among several bacterial species that have been implicated in asthma development, Haemophilus influenza and Streptococcus pneumoniae are the most cited $(148,149)$.

\section{Streptococcus pneumoniae}

Pneumococcal infections are key contributors to the high mortality rate among children in low- and low-and-middleincome countries $(150,151)$. Streptococcus pneumoniae, the cause of pneumococcal infections, is a Gramme-positive bacterium encapsulated by polysaccharides (152). The bacteria normally colonise the upper respiratory tracts and exist as a commensal organism in healthy hosts. However, it can cause disease in children under the age of 2 years and in adults over the age of 65 years and this is mainly due to the immaturity of the immune system and defectiveness that comes with age (153). S. pneumoniae can cause mild to more severe disease from local empyema, necrotising pneumonia to lung abscesses or systemic complications such as sepsis, septic shock, metastatic infection, multiorgan failure, acute respiratory distress syndrome, intravascular coagulation, and rarely death in children (154). S. pneumoniae infection can be treated with antibiotics which prevent prolonged hospitalisation and necrotising pneumonia in children (155). The introduction of pneumococcal conjugate vaccine PV7 and more recently PV13 which targets serotypes 1, 3, 5, 6A, 7F, and 19A has significantly reduced incidence and rates of hospitalisation due to empyema and necrotising pneumonia (156). Several studies have associated $S$. pneumoniae colonisation with allergic airway disease. In Denmark, a prospective study enrolled a total of 411 children born of asthmatic mothers that were followed from 4 weeks till the age of 3 years (157). Upon investigation it was discovered that wheezy episodes in the first 3 years of life were significantly associated with bacterial infection and $S$. pneumoniae was among the five bacterial species that were identified (Figure 3). Not only does colonisation with S. pneumoniae predispose children to wheezing but there are also implications for asthma development propelled by bacterial infection (158). Corroborating these findings is a neonatal mouse model, where an increase in airway hyperreactivity and an influx of inflammatory cells following S. pneumoniae induced pneumonia (149). These studies serve as proof of the ability of bacterial infections to cause or exacerbate airway allergic disease in neonates.

A different stance on the role of $S$. pneumoniae has been raised by several studies, whereby instead of a harmful effect, it can be used for therapeutic purposes $(159,160)$. In fact, this is not a new discovery, back in the 1980s it was noted that when asthmatic children were vaccinated with pneumococcal vaccine, asthma attack incidences were reduced by $56 \%$ (161). The action by which $S$. pneumoniae confers protection against asthma development and progression is through the suppression of both $\mathrm{TH} 1$ and $\mathrm{TH} 2$ responses, reduction of airway inflammatory cell recruitment and abrogated airway obstruction (160). Furthermore, an inverse correlation between the intensity of symptoms experienced by individuals during an asthma attack and $S$. pneumoniae colonisation has been reported. Although mechanistic studies still need to be carried out to fully elucidate this phenomenon, TNF- $\alpha$ is implicated as the immunoregulator of S. pneumoniae induced protective effects (159).

\section{Haemophilus influenzae}

Haemophilus influenzae is a gramme-negative anaerobic bacterium composed of both capsulated and non-capsulated strains responsible for a range of illnesses, from mild ear infection to invasive diseases like sepsis $(162,163)$. The classification of this bacterial species is based on the presence or lack of a polysaccharide capsule, with only one group of encapsulated type referred to as non-typeable $H$. influenzae implicated in various inflammatory disease exacerbation $(163,164)$. Naturally, $H$. influenzae forms part of healthy individuals' upper respiratory tract microbiome, with colonies detected within the first year of life, progressively expanding through to adulthood (165). Similar to what happens when $S$. pneumoniae predominates, a microflora that is dominantly characterised by $H$. influenzae is seen in individuals with airway diseases including asthma (166). Furthermore, $H$. influenzae has the ability to attach on several 
receptors of the airway epithelium, thus facilitating augmented inflammatory responses. The Intercellular adhesion molecule 1 (ICAM-1) is one of the receptors, whereby the interaction between this receptor and $H$. influenzae is fostered by the major outer membrane protein P5 fimbria (Figure 3) (164). The pathogenic role of $H$. influenzae extends beyond its involvement in the exacerbation of inflammatory conditions such as chronic obstructive pulmonary disease (COPD) and sinusitis (163). $H$. influenzae colonisation is also responsible for a substantial number of cases of invasive diseases in children below the age of 5 years and in adults over 50 years. Though the introduction of $H$. influenzae type $\mathrm{b}$ vaccine has had a great impact over the past 2 decades in reducing incidence rate of $H$. influenzae-related diseases, $H$. influenzae still possesses a great challenge as is it implicated in both asthma inception and disease exacerbation.

$H$. influenzae is among the top 5 mostly frequently detected pathogenic bacteria in children during early-life stages and is a common feature of neutrophilic asthma (158, 167). Experimentally, $H$. influenzae promotes a predominant neutrophilic inflammation through IL-17 induction, which in turn supresses $\mathrm{TH} 2$ responses, consequently propelling the development of non-controllable asthma (168). Moreover, exposure to $H$. influenzae over a long period of time has been proven detrimental as it triggers a TH17-dependent neutrophilia and the subsequent defective regulatory $\mathrm{T}$ cells (Tregs) response, leading to chronic inflammation and airway remodelling (Figure 3) (169). In humans, though the population of neutrophil-driven asthmatics is disproportionately comprised of adults, $H$. influenzae colonisation is one of the features of childhood neutrophilic asthma, the disease form that is usually unresponsive to treatment (158).

\section{MICROBIOME AND ASTHMA}

The microbiome is a significant part of our defence system made up of a community of commensal microorganisms whose main responsibility is to maintain immune homeostasis (170). However, an occasional imbalance in the microbial community occurs in certain individuals, and when this happens, a superfluous immune response is triggered leading to several immune disorders. Studies have associated particular imbalances with asthma development. For example, a shift from a predominantly Firmicutes and Proteobacteria to a Bacteroidetes dominant microbial community in neonatal mice lungs induces Tregs (171). The importance of T cell differentiation into Tregs and their role in regulating allergic responses is well-documented (172-174). Additionally, lung microbiota formation is one of the identifiable factors that set the trajectory of our respiratory health (Figure 3). Among the first bacterial species to appear (at $24 \mathrm{~h}$ post-birth) are communities of Staphylococcus spp., Streptococcus spp., and Neisseria spp., to name a few (175). Within the first 2 months of life the microbiome gradually diversifies and matures to a profile comparable to that of adults. Immediately following the peak of diversity and maturity, population readjustment occurs, with Staphylococcus spp. presence showing a decline as early as 7 weeks postpartum (175), which is replaced by an abundance in Streptococcus spp., among other bacterial species. Streptococcus spp. is one of the species well-known for its association with infant-wheezing at 1 month (158), a known predisposing factor of asthma development (Figure 3). The presence, as well as the absence of these colonising bacterial species has been directly correlated to the control or lack thereof of allergic responses. For example, the aforementioned shift to a more Bacteroidetes biassed population triggers allergen tolerance through Treg induction in a programmed death ligand 1 (PDL1)-dependent manner (171).

The development of early microbiota is dependent on several factors. While neonatal microbial profile is vastly influenced by the mode of delivery at birth, other studies have also shown how the use of antibiotics can lead to an antibiotic-driven microbiome dysbiosis which is associated with an increase in asthma burden in children (176). A prospective study looking at the impact of mode of delivery on microbiome development found that delivery by Caesarean section affects the rate at which the microbial communities are formed as well as the abundance of respiratory-health related microbiota (177). The consequence of the aforementioned events is said to influence respiratory health from childhood through to adulthood, which then corroborate the contributory role that lung dysbiosis has on asthma inception. Antibiotics, on the other hand, do not only disturb lung homeostasis by acting directly on commensal bacteria, they also compromise the ability of the immune system to distinguish between self and non-self-antigen (178). Since commensal bacteria are essential triggers of the immune system's regulatory cells, when antibiotics are administered, they can, non-selectively, strip away the essential bacteria, leaving the host susceptible to allergic disease development. Several studies have correlated asthma development to early-life antibiotic exposure (178-181). This then evidently demonstrates the importance of bacterial colonisation at infancy and the role it plays as a determinant of respiratory health and potential asthma development.

Mechanisms of how microbiota can limit asthma development at an early age are not fully understood. Some studies have suggested that microbial metabolites released by good microbiota act directly on pathogenic bacterial species to limit their growth by either reducing essential nutrient availability or promoting toxic by-products that can inhibit microbial growth $(182,183)$. Mechanistically, gut microbiota fuelled by selective antibody pressure enhance capacity of L-tyrosine metabolising species, which in turn increases levels of p-cresol sulphate. P-cresol sulphate was able to reduce allergic asthma through reduction of epithelial derived CCL20, a chemokine known to drive type 2 allergic airway inflammation.

\section{ASTHMA MOUSE MODELS}

Animal models have proven to be critical in asthma research, simple because they develop features of the disease similar to humans when exposed to ovalbumin (OVA) complexed to adjuvant alum or house dust mite, a more complex and relevant allergen (184-187). Key pathophysiological features of 
asthma that can be reproduced in animals include increased allergen-specific IgE, increased eosinophils, TH2 cells and airway hyperreactivity which can be induced by bronchoconstrictors (187). Availability of a wide array of genetically deficient and transgenic mice strains is attractive for studies of pre-clinical disease mechanisms. Although adult mouse studies have been used successfully for over 5 decades to mimic asthma in humans, models that mimic early development, a crucial stage in disease onset has been difficult (188). To fully appreciate early determinants of asthma pathophysiology, several studies have recapitulated these early events in animal models of allergic asthma $(188,189)$. Saglani et al. (188) developed a neonatal mouse model that has been widely adapted. In this study, they used a more natural route where 3-day old mice were sensitised intranasally with HDM to investigate earlyonset of asthma (188). At steady state, innate lymphoid cells (ILC2s) producing IL-13 dominate the first 10 days of life in an ST2-dependent manner (190), whereas during HDM exposure CD4 T cells producing IL-13 are thought to be the main contributor toward allergic airway inflammation (41). Interestingly, neonatal 3-day-old mice deficient of ST2 or lacking IL-13 production specifically in ILC2 develop AHR, whereas those lacking IL-13-specifically in CD3 T cells are unable to develop AHR (41). Other studies using Alternaria alternata, a fungi mainly associated with steroid resistant asthma in children and adults have shown that this IL-33-dependent allergic airway inflammatory response can only be treated with steroids (190192). Interestingly, this TH2-biassed immune phenotype is also characterised by M2 macrophages that favour resolution of inflammation and protect the vulnerable developing lung (24). These macrophages are dependent on TGF- $\beta$ signalling which sustain these cells in the first few days of life and promote TH2 responses (193).

$\mathrm{T}$ helper 2 environment dominates early stages of life, partly due to an evolutionary protective response in pregnant mothers which is transferred to offspring mainly to protect against foreign pathogens in a newborn (194). What has been unclear is how children are the most vulnerable to developing allergic responses, even in the presence of constant microbial exposure which is thought to be protective through hygiene hypothesis (126). A recent study in an HDM model elucidated mechanisms that drive early-onset of asthma in neonatal mice. Here the authors showed that when mice are sensitised using HDM and low dose LPS, they respond differently depending on the age (195). While low dose LPS was able to suppress TH2 allergic airway inflammation in adult mice, in neonatal mice the $\mathrm{TH} 2$ allergic airway inflammation was sustained (195). Mechanistically, antigen presenting cells in neonates were hypo responsive to LPS through reduced expression of TLR-4. This reduced TLR-4 signal led to reduced TNF- $\alpha$ dependent activation of migratory DCs, which induced less T-bet transcription and less IL-12. This reduced IL-12 expression led to reduced polarisation of $\mathrm{T}$ cells toward $\mathrm{TH} 1$ lineage and increased transcription of GATA-3 and TH2 cytokines in neonates (195).
This study is well within the premises of the hygiene hypothesis, where the intensity of germ exposure is correlated to protection from allergic disease development.

\section{CONCLUDING REMARKS}

Childhood asthma is a chronic disease affecting close to 9 million children in the US alone. The development of asthma is complex and is likely to be influenced by genetics and environment factors in utero and postnatally. The lung completes its final maturation in the first 3 years of life which makes it vulnerable to viral and bacterial infections, which can set a detrimental trajectory in lung function. Understanding which factors are critical in poor lung function leading to early wheezing is an important question. The heterogeneity in immune profiles observed in children with asthma has not been explored in detailed, partly due to difficulties in accessing bronchoscopy in children. Non-invasive methods such as bronchial brushing or nasal brushings have proven to be reliable, showing great similarities in gene expression between lung bronchial biopsies and nasal brushings $(17,196)$. Nasal brushing transcriptomics showing TH2 high and TH2 low asthma, highly correlate with eosinophil levels observed in blood, which suggests that more complex cases of asthma can be detected this way. There is a need to closely monitor birth cohort studies and sample children non-invasively at different time points to fully understand what immunological markers or defects can be correlated with early development of poor lung function and early wheezing. There is also a need to consider other chronic diseases in mothers, such as HIV, which could have negative impact on normal development of children, leading to poor lung function and early wheezing. Animal models are vital in understanding the early development of asthma, and further work in this area to better model human disease may lead to improved therapeutics.

\section{AUTHOR CONTRIBUTIONS}

SH and FB conceived the idea. NM and PI contributed equally to the writing of this manuscript. NM, PI, FB, and $\mathrm{SH}$ wrote the paper. All authors contributed to the article and approved the submitted version.

\section{FUNDING}

This work was supported by ICGEB, Cape Town Component, Medical Research Council (MRC) South Africa as well as support by the South African National Research Foundation (NRF) Research Chair initiative (SARChi) and Wellcome Trust CIDRI-Africa $(203135 Z / 16 / Z)$ to FB. SH was supported by NRF Thuthuka Grant (117721), South African MRC under a Self-initiated grant. NM was supported by South African MRC PhD Fellowship. PI was supported by NRF PhD Scholarship. 


\section{REFERENCES}

1. Mizgerd JP. Lung infection-a public health priority. PLoS Med. (2006) 3:e76. doi: 10.1371/journal.pmed.0030076

2. Troy NM, Bosco A. Respiratory viral infections and host responses; insights from genomics. Respiratory Res. (2016) 17:156. doi: 10.1186/s12931-016-0474-9

3. Khetsuriani N, Kazerouni NN, Erdman DD, Lu X, Redd SC, Anderson LJ, et al. Prevalence of viral respiratory tract infections in children with asthma. J Allergy Clin Immunol. (2007) 119:314-21. doi: 10.1016/j.jaci.2006.08.041

4. Liu L, Johnson HL, Cousens S, Perin J, Scott S, Lawn JE, et al. Global, regional, and national causes of child mortality: an updated systematic analysis for 2010 with time trends since 2000. Lancet. (2012) 379:215161. doi: 10.1016/S0140-6736(12)60560-1

5. Schwarze J, Gelfand EW. Respiratory viral infections as promoters of allergic sensitization and asthma in animal models. Euro Respir J. (2002) 19:341. doi: 10.1183/09031936.02.00254302

6. Wenzel SE. Asthma phenotypes: the evolution from clinical to molecular approaches. Nat Med. (2012) 18:716-25. doi: 10.1038/nm.2678

7. World Health Organization. Chronic Respiratory Disease: Asthma. Geneva: World Health Organization (2020).

8. Darveaux JI, Lemanske RF Jr. Infection-related asthma. J Allergy Clin Immunol Pract. (2014) 2:658-63. doi: 10.1016/j.jaip.2014.09.011

9. Jartti T, Bønnelykke K, Elenius V, Feleszko W. Role of viruses in asthma. Semin Immunopathol. (2020) 42:61-74. doi: 10.1007/s00281-020-00781-5

10. Beigelman A, Bacharier LB. Management of preschool children with recurrent wheezing: lessons from the NHLBI's asthma research networks. $J$ Allergy Clin Immunol Prac. (2016) 4:1-8. doi: 10.1016/j.jaip.2015.10.003

11. Bertino JS. Cost burden of viral respiratory infections: issues for formulary decision makers. Am J Med. (2002) 112:429. doi: 10.1016/S0002-9343(01)01063-4

12. Ahanchian $\mathrm{H}$, Jones CM, Chen YS, Sly PD. Respiratory viral infections in children with asthma: do they matter and can we prevent them? BMC Pediatr. (2012) 12:147. doi: 10.1186/1471-2431-12-147

13. Gern JE. Viral respiratory infection and the link to asthma. Pediatr Infect Dis J. (2004) 23:S78-86. doi: 10.1097/01.inf.0000108196.46134.a6

14. Turunen R, Koistinen A, Vuorinen T, Arku B, Söderlund-Venermo M, Ruuskanen $\mathrm{O}$, et al. The first wheezing episode: respiratory virus etiology, atopic characteristics, illness severity. Pediatr Allergy Immunol. (2014) 25:796-803. doi: $10.1111 /$ pai.12318

15. Toews G. Impact of bacterial infections on airway diseases. Euro Respir Rev. (2005) 14:62-8. doi: 10.1183/09059180.05.00009504

16. Robinson DS, Hamid Q, Ying S, Tsicopoulos A, Barkans J, Bentley AM, et al. Predominant TH2-like bronchoalveolar Tlymphocyte population in atopic asthma. $N$ Engl J Med. (1992) 326:298-304. doi: 10.1056/NEJM199201303260504

17. Peters MC, Mekonnen ZK, Yuan S, Bhakta NR, Woodruff PG, Fahy JV. Measures of gene expression in sputum cells can identify TH2-high and TH2-low subtypes of asthma. J Allergy Clin Immunol. (2014) 133:38894. doi: 10.1016/j.jaci.2013.07.036

18. Raundhal M, Morse C, Khare A, Oriss TB, Milosevic J, Trudeau J, et al. High IFN- $\gamma$ and low SLPI mark severe asthma in mice and humans. J Clin Investig. (2015) 125:3037-50. doi: 10.1172/JCI80911

19. Lloyd CM, Saglani S. Opening the window of immune opportunity: treating childhood asthma. Trends Immunol. (2019) 40:786-98. doi: 10.1016/j.it.2019.07.004

20. Rose S, Lichtenheld M, Foote MR, Adkins B. Murine neonatal CD4+ cells are poised for rapid Th2 effector-like function. J Immunol. (2007) 178:266778. doi: 10.4049/jimmunol.178.5.2667

21. Makris S, Johansson C. R848 or influenza virus can induce potent innate immune responses in the lungs of neonatal mice. Mucosal Immunol. (2021) 14:267-76. doi: 10.1038/s41385-020-0314-6

22. Chen J-C, Chan C-C, Wu C-J, Ou L-S, Yu H-Y, Chang H-L, et al. Fetal phagocytes take up allergens to initiate T-helper cell type 2 immunity and facilitate allergic airway responses. Am J Respir Crit Care Med. (2016) 194:934-47. doi: 10.1164/rccm.201508-1703OC

23. de Kleer IM, Kool M, de Bruijn MJ, Willart M, van Moorleghem J, Schuijs MJ, et al. Perinatal activation of the interleukin-33 pathway promotes type 2 immunity in the developing lung. Immunity. (2016) 45:128598. doi: 10.1016/j.immuni.2016.10.031

24. Saluzzo S, Gorki A-D, Rana BMJ, Martins R, Scanlon S, Starkl P, et al. Firstbreath-induced type 2 pathways shape the lung immune environment. Cell Reports. (2017) 18:1893-905. doi: 10.1016/j.celrep.2017.01.071

25. Lloyd CM, Hessel EM. Functions of T cells in asthma: more than just TH2 cells. Nat Rev Immunol. (2010) 10:838-48. doi: 10.1038/nri2870

26. Kudo M, Ishigatsubo Y, Aoki I. Pathology of asthma. Front Microbiol. (2013) 4:263. doi: 10.3389/fmicb.2013.00263

27. Barnes PJ. Immunology of asthma and chronic obstructive pulmonary disease. Nat Rev Immunol. (2008) 8:183-92. doi: 10.1038/nri2254

28. Schwartz HJ, Lowell FC, Melby JC. Steroid resistance in bronchial asthma. Ann Internal Med. (1968) 68:1141. doi: 10.7326/0003-4819-68-5-1141_3

29. Barnes PJ, Adcock IM. Glucocorticoid resistance in inflammatory diseases. Lancet. (2009) 373:1905-17. doi: 10.1016/S0140-6736(09)60326-3

30. Trevor J, Deshane J. Refractory asthma: mechanisms, targets, and therapy. Allergy. (2014) 69:817-27. doi: 10.1111/all.12412

31. Carmichael J, Paterson IC, Diaz P, Crompton G, Kay A, Grant I. Corticosteroid resistance in chronic asthma. Br Med J. (1981) 282:141922. doi: $10.1136 / \mathrm{bmj} .282 .6274 .1419$

32. Wadhwa R, Dua K, Adcock IM, Horvat JC, Kim RY, Hansbro PM. Cellular mechanisms underlying steroid-resistant asthma. Eur Respir Rev. (2019) 28:190096. doi: 10.1183/16000617.0096-2019

33. Adcock IM, Ford PA, Bhavsar P, Ahmad T, Chung KF. Steroid resistance in asthma: mechanisms and treatment options. Curr Allergy Asthma Rep. (2008) 8:171. doi: 10.1007/s11882-008-0028-4

34. Svenningsen S, Nair P. Asthma endotypes and an overview of targeted therapy for asthma. Front Med. (2017) 4:158. doi: 10.3389/fmed.2017.00158

35. Wenzel SE. Asthma: defining of the persistent adult phenotypes. Lancet. (2006) 368:804-13. doi: 10.1016/S0140-6736(06)69290-8

36. Anderson GP. Endotyping asthma: new insights into key pathogenic mechanisms in a complex, heterogeneous disease. Lancet. (2008) 372:110719. doi: 10.1016/S0140-6736(08)61452-X

37. Fahy JV. Type 2 inflammation in asthma - present in most, absent in many. Nat Rev Immunol. (2015) 15:57-65. doi: 10.1038/nri3786

38. Rodriguez-Rodriguez N, Gogoi M, McKenzie ANJ. Group 2 innate lymphoid cells: team players in regulating asthma. Annu Rev Immunol. (2021) 39:16798. doi: 10.1146/annurev-immunol-110119-091711

39. Gibson PG, Simpson JL, Saltos N. Heterogeneity of airway inflammation in persistent asthma: evidence of neutrophilic inflammation and increased sputum interleukin-8. Chest. (2001) 119:1329-36. doi: 10.1378/chest.119.5.1329

40. Gauthier M, Chakraborty K, Oriss TB, Raundhal M, Das S, Chen J, et al. Severe asthma in humans and mouse model suggests a CXCL10 signature underlies corticosteroid-resistant Th1 bias. JCI Insight. (2017) 2:e94580. doi: 10.1172/jci.insight.94580

41. Saglani S, Gregory LG, Manghera AK, Branchett WJ, Uwadiae F, Entwistle LJ, et al. Inception of early-life allergen-induced airway hyperresponsiveness is reliant on IL-13+CD4+ T cells. Sci Immunol. (2018) 3:eaan4128. doi: 10.1126/sciimmunol.aan4128

42. Teague WG, Lawrence MG, Shirley DT, Garrod AS, Early SV, Payne JB, et al. Lung lavage granulocyte patterns and clinical phenotypes in children with severe, therapy-resistant asthma. J Allergy Clin Immunol Pract. (2019) 7:1803-12. e10. doi: 10.1016/j.jaip.2018.12.027

43. Steinke JW, Lawrence MG, Teague WG, Braciale TJ, Patrie JT, Borish L. Bronchoalveolar lavage cytokine patterns in children with severe neutrophilic and paucigranulocytic asthma. J Allergy Clin Immunol. (2021) 147:686-93. e3. doi: 10.1016/j.jaci.2020.05.039

44. Andersson CK, Adams A, Nagakumar P, Bossley C, Gupta A, De Vries D, et al. Intraepithelial neutrophils in pediatric severe asthma are associated with better lung function. J Allergy Clin Immunol. (2017) 139:1819-29. e11. doi: 10.1016/j.jaci.2016.09.022

45. Fleming L, Koo M, Bossley CJ, Nagakumar P, Bush A, Saglani S. The utility of a multidomain assessment of steroid response for predicting clinical response to omalizumab. J Allergy Clin Immunol. (2016) 138:2924. doi: 10.1016/j.jaci.2015.12.1317

46. Wisniewski JA, Muehling LM, Eccles JD, Capaldo BJ, Agrawal R, Shirley DA, et al. TH1 signatures are present in the lower airways of children with 
severe asthma, regardless of allergic status. J Allergy Clin Immunol. (2018) 141:2048-60.e13. doi: 10.1016/j.jaci.2017.08.020

47. Liu S, Verma M, Michalec L, Liu W, Sripada A, Rollins D, et al. Steroid resistance of airway type 2 innate lymphoid cells from patients with severe asthma: the role of thymic stromal lymphopoietin. J Allergy Clin Immunol. (2018) 141:257-68 e6. doi: 10.1016/j.jaci.2017.03.032

48. Nagakumar P, Denney L, Fleming L, Bush A, Lloyd CM, Saglani S. Type 2 innate lymphoid cells in induced sputum from children with severe asthma. J Allergy Clin Immunol. (2016) 137:624-6.e6. doi: 10.1016/j.jaci.2015.06.038

49. Nagakumar P, Puttur F, Gregory LG, Denney L, Fleming L, Bush A, et al. Pulmonary type-2 innate lymphoid cells in paediatric severe asthma: phenotype and response to steroids. Eur Respir J. (2019) 54:1801809. doi: 10.1183/13993003.01809-2018

50. van der Ploeg EK, Golebski K, van Nimwegen M, Fergusson JR, Heesters BA, Martinez-Gonzalez I, et al. Steroid-resistant human inflammatory ILC2s are marked by $\mathrm{CD} 45 \mathrm{RO}$ and elevated in type 2 respiratory diseases. Sci Immunol. (2021) 6:eabd3489. doi: 10.1126/sciimmunol.abd3489

51. Morgan WJ, Stern DA, Sherrill DL, Guerra S, Holberg CJ, Guilbert TW, et al. Outcome of asthma and wheezing in the first 6 years of life: followup through adolescence. Am J Respir Crit Care Med. (2005) 172:12538. doi: $10.1164 / \mathrm{rccm} .200504-525 \mathrm{OC}$

52. Yunginger JW, Reed CE, O'Connell EJ, Melton LJ 3rd, O'Fallon WM, Silverstein MD. A community-based study of the epidemiology of asthma. Incidence rates, 1964-1983. Am Rev Respir Dis. (1992) 146:88894. doi: $10.1164 / \mathrm{ajrccm} / 146.4 .888$

53. Stern DA, Morgan WJ, Wright AL, Guerra S, Martinez FD. Poor airway function in early infancy and lung function by age 22 years: a non-selective longitudinal cohort study. Lancet. (2007) 370:75864. doi: 10.1016/S0140-6736(07)61379-8

54. Borrego LM, Stocks J, Leiria-Pinto P, Peralta I, Romeira AM, Neuparth $\mathrm{N}$, et al. Lung function and clinical risk factors for asthma in infants and young children with recurrent wheeze. Thorax. (2009) 64:203. doi: 10.1136/thx.2008.099903

55. Martinez FD, Wright AL, Taussig LM, Holberg CJ, Halonen M, Morgan WJ. Asthma and wheezing in the first six years of life. The Group Health Medical Associates. N Engl J Med. (1995) 332:1338. doi: 10.1056/NEJM199501193320301

56. Tai A, Tran H, Roberts M, Clarke N, Gibson AM, Vidmar S, et al. Outcomes of childhood asthma to the age of 50 years. J Allergy Clin Immunol. (2014) 133:1572-8.e3. doi: 10.1016/j.jaci.2013.12.1033

57. Bush A. Low lung function in young adult life is associated with early mortality. Am J Respir Crit Care Med. (2018) 197:538-9. doi: 10.1164/rccm.201707-1416LE

58. Hüls A, Vanker A, Gray D, Koen N, MacIsaac JL, Lin DT, et al. Genetic susceptibility to asthma increases the vulnerability to indoor air pollution. Euro Respir J. (2020) 55:1901831. doi: 10.1183/13993003.01831-2019

59. Saglani S, Malmström K, Pelkonen AS, Malmberg LP, Lindahl H, Kajosaari $\mathrm{M}$, et al. Airway remodeling and inflammation in symptomatic infants with reversible airflow obstruction. Am J Respir Crit Care Med. (2005) 171:722-7. doi: 10.1164/rccm.200410-1404OC

60. Altman MC, Gill MA, Whalen E, Babineau DC, Shao B, Liu AH, et al. Transcriptome networks identify mechanisms of viral and nonviral asthma exacerbations in children. Nat Immunol. (2019) 20:637-51. doi: 10.1038/s41590-019-0347-8

61. Denney L, Adam Byrne J, Thomas Shea J, James Buckley S, James Pease E, Gaelle Herledan MF, et al. Pulmonary epithelial cell-derived cytokine TGF- $\beta 1$ Is a critical cofactor for enhanced innate lymphoid cell function. Immunity. (2015) 43:945-58. doi: 10.1016/j.immuni.2015.10.012

62. Löser S, Gregory LG, Zhang Y, Schaefer K, Walker SA, Buckley J, et al. Pulmonary ORMDL3 is critical for induction of Alternariainduced allergic airways disease. J Allergy Clin Immunol. (2017) 139:1496507.e3. doi: 10.1016/j.jaci.2016.07.033

63. Gui H, Levin AM, Hu D, Sleiman P, Xiao S, Mak ACY, et al. Mapping the 17q12-21.1 locus for variants associated with early-onset asthma in African Americans. Am J Respir Crit Care Med. (2021) 203:42436. doi: $10.1164 / \mathrm{rccm} .202006-2623 \mathrm{OC}$

64. Zhang Y, Willis-Owen SA, Spiegel S, Lloyd CM, Moffatt MF, Cookson WO. The ORMDL3 asthma gene regulates ICAM1 and has multiple effects on cellular inflammation. Am J Respir Crit Care Med. (2019) 199:47888. doi: $10.1164 / \mathrm{rccm} .201803-0438 \mathrm{OC}$

65. Weinberg GA, Erdman DD, Edwards KM, Hall CB, Walker FJ, Griffin MR, et al. Superiority of reverse-transcription polymerase chain reaction to conventional viral culture in the diagnosis of acute respiratory tract infections in children. The J Infect Dis. (2004) 189:706-10. doi: $10.1086 / 381456$

66. Oliver BG, Robinson P, Peters M, Black J. Viral infections and asthma: an inflammatory interface? Eur Respiratory Soc. (2014) 44:16666-1681. doi: 10.1183/09031936.00047714

67. Busse WW, Lemanske RF Jr, Gern JE. Role of viral respiratory infections in asthma and asthma exacerbations. Lancet. (2010) 376:82634. doi: 10.1016/S0140-6736(10)61380-3

68. Vandini S, Biagi C, Fischer M, Lanari M. Impact of rhinovirus infections in children. Viruses. (2019) 11:521. doi: 10.3390/v11060521

69. Hui D, Chan P. PNEUMONIA| Viral. Encycl Respir Med. (2006) 45666. doi: 10.1016/B0-12-370879-6/00317-3

70. Jartti T, Gern JE. Role of viral infections in the development and exacerbation of asthma in children. J Allergy Clin Immunol. (2017) 140:895906. doi: 10.1016/j.jaci.2017.08.003

71. Committee on Infectious Diseases. Updated guidance for palivizumab prophylaxis among infants and young children at increased risk of hospitalization for respiratory syncytial virus infection. Pediatrics. (2014) 134:e620-38. doi: 10.1542/peds.2014-1666

72. Inoue Y, Shimojo N. Epidemiology of virus-induced wheezing/asthma in children. Front Microbiol. (2013) 4:391. doi: 10.3389/fmicb.2013.00391

73. Wu P, Hartert TV. Evidence for a causal relationship between respiratory syncytial virus infection and asthma. Expert Rev Anti Infect Ther. (2011) 9:731-45. doi: 10.1586/eri.11.92

74. Simões EAF, Carbonell-Estrany X, Rieger CHL, Mitchell I, Fredrick L, Groothuis JR. The effect of respiratory syncytial virus on subsequent recurrent wheezing in atopic and nonatopic children. J Allergy Clin Immunol. (2010) 126:256-62. doi: 10.1016/j.jaci.2010.05.026

75. Johnson SM, McNally BA, Ioannidis I, Flano E, Teng MN, Oomens $A G$, et al. Respiratory syncytial virus uses CX3CR1 as a receptor on primary human airway epithelial cultures. PLoS Pathog. (2015) 11:e1005318. doi: 10.1371/journal.ppat.1005318

76. Hansbro NG, Horvat JC, Wark PA, Hansbro PM. Understanding the mechanisms of viral induced asthma: new therapeutic directions. Pharmacol Ther. (2008) 117:313-53. doi: 10.1016/j.pharmthera.2007.11.002

77. Johnson JE, Gonzales RA, Olson SJ, Wright PF, Graham BS. The histopathology of fatal untreated human respiratory syncytial virus infection. Mod Pathol. (2007) 20:108-19. doi: 10.1038/modpathol. 3800725

78. McIntyre CL, Knowles NJ, Simmonds P. Proposals for the classification of human rhinovirus species A, B and C into genotypically assigned types. $J$ General Virol. (2013) 94:1791. doi: 10.1099/vir.0.053686-0

79. Stone CA, Miller EK. Understanding the association of human rhinovirus with asthma. Clin Vaccine Immunol. (2016) 23:6-10. doi: 10.1128/CVI.00414-15

80. Heinonen S, Jartti T, Garcia C, Oliva S, Smitherman C, Anguiano E, et al. Rhinovirus detection in symptomatic and asymptomatic children: value of host transcriptome analysis. Am J Respir Crit Care Med. (2016) 193:77282. doi: $10.1164 / \mathrm{rccm} .201504-07490 \mathrm{OC}$

81. Toussaint M, Jackson DJ, Swieboda D, Guedán A, Tsourouktsoglou T-D, Ching YM, et al. Host DNA released by NETosis promotes rhinovirusinduced type-2 allergic asthma exacerbation. Nat Med. (2017) 23:68191. doi: $10.1038 / \mathrm{nm} .4332$

82. Bønnelykke K, Sleiman P, Nielsen K, Kreiner-Møller E, Mercader JM, Belgrave D, et al. A genome-wide association study identifies CDHR3 as a susceptibility locus for early childhood asthma with severe exacerbations. Nat Genet. (2014) 46:51-5. doi: 10.1038/ng.2830

83. Holgate ST. Rhinoviruses in the pathogenesis of asthma: the bronchial epithelium as a major disease target. J Allergy Clin Immunol. (2006) 118:58790. doi: $10.1016 /$ j.jaci.2006.06.023

84. Hodinka RL. Respiratory RNA viruses. In: Diagnostic Microbiology of the Immunocompromised Host, Chapter 11. Washington, DC: Wiley (2016). p. 233-71. doi: 10.1128/9781555819040.ch11 
85. Mishin VP, Patel MC, Chesnokov A, De La Cruz J, Nguyen HT, Lollis L, et al. Susceptibility of influenza A, B, C, and D viruses to baloxavir. Emerg Infect Dis. (2019) 25:1969. doi: 10.3201/eid2510.190607

86. Chen Y-Q, Wohlbold TJ, Zheng N-Y, Huang M, Huang Y, Neu KE, et al. Influenza infection in humans induces broadly cross-reactive and protective neuraminidase-reactive antibodies. Cell. (2018) 173:417-29. e10. doi: 10.1016/j.cell.2018.03.030

87. Obuchi M, Adachi Y, Takizawa T, Sata T. Influenza A (H1N1) pdm09 virus and asthma. Front Microbiol. (2013) 4:307. doi: 10.3389/fmicb.2013.00307

88. Veerapandian $\mathrm{R}$, Snyder JD, Samarasinghe AE. Influenza in asthmatics: for better or for worse? Front Immunol. (2018) 9:1843. doi: $10.3389 /$ fimmu.2018.01843

89. Effler PV. Every year is an influenza pandemic for children: can we stop them? Pediatrics. (2012) 130:554-6. doi: 10.1542/peds.2012-1171

90. Restori KH, Srinivasa BT, Ward BJ, Fixman ED. Neonatal immunity, respiratory virus infections, and the development of asthma. Front Immunol. (2018) 9:1249. doi: 10.3389/fimmu.2018.01249

91. Rust MJ, Lakadamyali M, Zhang F, Zhuang X. Assembly of endocytic machinery around individual influenza viruses during viral entry. Nat Struct Mol Biol. (2004) 11:567-73. doi: 10.1038/nsmb769

92. Rossman JS, Lamb RA. Influenza virus assembly and budding. Virology. (2011) 411:229-36. doi: 10.1016/j.virol.2010.12.003

93. Herold S, Becker C, Ridge KM, Budinger GS. Influenza virus-induced lung injury: pathogenesis and implications for treatment. Eur Respir J. (2015) 45:1463-78. doi: 10.1183/09031936.00186214

94. Chang Y-J, Kim HY, Albacker LA, Baumgarth N, McKenzie AN, Smith $\mathrm{DE}$, et al. Innate lymphoid cells mediate influenza-induced airway hyperreactivity independently of adaptive immunity. Nat Immunol. (2011) 12:6318. doi: $10.1038 /$ ni.2045

95. Li Y, Li H, Fan R, Wen B, Zhang J, Cao X, et al. Coronavirus infections in the central nervous system and respiratory tract show distinct features in hospitalized children. Intervirology. (2016) 59:1639. doi: $10.1159 / 000453066$

96. Chan JF-W, Yuan S, Kok K-H, To KK-W, Chu H, Yang J, et al. A familial cluster of pneumonia associated with the 2019 novel coronavirus indicating person-to-person transmission: a study of a family cluster. Lancet. (2020) 395:514-23. doi: 10.1016/S0140-6736(20)30154-9

97. Selva KJ, van de Sandt CE, Lemke MM, Lee CY, Shoffner SK, Chua BY, et al. Systems serology detects functionally distinct coronavirus antibody features in children and elderly. Nat Commun. (2021) 12:2037. doi: 10.1038/s41467-021-22236-7

98. Sajuthi SP, DeFord P, Jackson ND, Montgomery MT, Everman JL, Rios $\mathrm{CL}$, et al. Type 2 and interferon inflammation regulate SARS-CoV-2 entry factor expression in the airway epithelium. Nat Commun. (2020) 11:5139. doi: 10.1038/s41467-020-18781-2

99. Peters MC, Sajuthi S, Deford P, Christenson S, Rios CL, Montgomery MT, et al. COVID-19-related genes in sputum cells in asthma. Relationship to demographic features corticosteroids. Am J Respir Crit Care Med. (2020) 202:83-90. doi: 10.1164/rccm.202003-0821OC

100. Chatziparasidis G, Kantar A. COVID-19 in children with asthma. Lung. (2021) 199:7-12. doi: 10.1007/s00408-021-00419-9

101. Li W, Moore MJ, Vasilieva N, Sui J, Wong SK, Berne MA, et al. Angiotensinconverting enzyme 2 is a functional receptor for the SARS coronavirus. Nature. (2003) 426:450-4. doi: 10.1038/nature02145

102. Muus C, Luecken MD, Eraslan G, Waghray A, Heimberg G, Sikkema L, et al. The NHLBI lungMAP consortium, and the human cell atlas lung biological network. Integrated analyses of single-cell atlases reveal age, gender, and smoking status associations with cell type-specific expression of mediators of SARS-CoV-2 viral entry and highlights inflammatory programs in putative target cells. bioRxiv. (2020). doi: 10.1101/2020.04.19. 049254

103. Finney LJ, Glanville N, Farne H, Aniscenko J, Fenwick P, Kemp SV, et al. Inhaled corticosteroids downregulate the SARS-CoV-2 receptor ACE2 in COPD through suppression of type I interferon. J Allergy Clin Immunol. (2020) 147:510-9. doi: 10.1101/2020.06.13.149039

104. Steinman JB, Lum FM, Ho PP-K, Kaminski N, Steinman L. Reduced development of COVID-19 in children reveals molecular checkpoints gating pathogenesis illuminating potential therapeutics.
Proc Natl Acad Sci USA. (2020) 117:24620-6. doi: 10.1073/pnas.2012 358117

105. Von Mollendorf C, Von Gottberg A, Tempia S, Meiring S, De Gouveia L, Quan V, et al. Increased risk for and mortality from invasive pneumococcal disease in HIV-exposed but uninfected infants aged $<1$ year in South Africa, 2009-2013. Clin Infect Dis. (2015) 60:1346-56. doi: $10.1093 /$ cid/civ059

106. Taron-Brocard C, Le Chenadec J, Faye A, Dollfus C, Goetghebuer T, Gajdos $\mathrm{V}$, et al. Increased risk of serious bacterial infections due to maternal immunosuppression in HIV-exposed uninfected infants in a European country. Clin Infect Dis. (2014) 59:1332-45. doi: 10.1093/cid/ciu586

107. Cohen C, Moyes J, Tempia S, Groome M, Walaza S, Pretorius $\mathrm{M}$, et al. Epidemiology of acute lower respiratory tract infection in HIV-exposed uninfected infants. Pediatrics. (2016) 137:e20153272. doi: $10.1542 /$ peds.2015-3272

108. Le Roux DM, Nicol MP, Myer L, Vanker A, Stadler JA, von Delft E, et al. Lower respiratory tract infections in children in a well-vaccinated South African birth cohort: spectrum of disease and risk factors. Clin Infect Dis. (2019) 69:1588-96. doi: 10.1093/cid/ciz017

109. McNally LM, Jeena PM, Gajee K, Thula SA, Sturm AW, Cassol S, et al. Effect of age, polymicrobial disease, and maternal HIV status on treatment response and cause of severe pneumonia in South African children: a prospective descriptive study. Lancet. (2007) 369:144051. doi: 10.1016/S0140-6736(07)60670-9

110. Marinda E, Humphrey JH, Iliff PJ, Mutasa K, Nathoo KJ, Piwoz EG, et al. Child mortality according to maternal and infant HIV status in Zimbabwe. Pediatric Infect Dis J. (2007) 26:519-26. doi: 10.1097/01.inf.0000264527.69954.4c

111. Preidis GA, McCollum ED, Mwansambo C, Kazembe PN, Schutze GE, Kline MW. Pneumonia and malnutrition are highly predictive of mortality among African children hospitalized with human immunodeficiency virus infection or exposure in the era of antiretroviral therapy. J Pediatrics. (2011) 159:484-9. doi: 10.1016/j.jpeds.2011.02.033

112. Pacheco SE, McIntosh K, Lu M, Mofenson LM, Diaz C, Foca M, et al. Effect of perinatal antiretroviral drug exposure on hematologic values in HIV-uninfected children: an analysis of the women and infants transmission study. J Infect Dis. (2006) 194:1089-97. doi: 10.1086/507645

113. Study EC. Levels and patterns of neutrophil cell counts over the first 8 years of life in children of HIV-1-infected mothers. AIDS. (2004) 18:200917. doi: 10.1097/00002030-200410210-00005

114. Bailey H, Zash R, Rasi V, Thorne C. HIV treatment in pregnancy. Lancet HIV. (2018) 5:e457-67. doi: 10.1016/S2352-3018(18)30059-6

115. Gray DM, Wedderburn CJ, MacGinty RP, McMillan L, Jacobs C, Stadler JA, et al. Impact of HIV and antiretroviral drug exposure on lung growth and function over 2 years in an African Birth Cohort. AIDS. (2020) 34:549. doi: 10.1097/QAD.0000000000002444

116. Scott S, Moss WJ, Cousens S, Beeler JA, Audet UA, Mugala N, et al. The influence of HIV-1 exposure and infection on levels of passively acquired antibodies to measles virus in Zambian infants. Clin Infect Dis. (2007) 45:1417-24. doi: 10.1086/522989

117. Velilla PA, Rugeles MT, Chougnet CA. Defective antigen-presenting cell function in human neonates. Clin Immunol. (2006) 121:2519. doi: 10.1016/j.clim.2006.08.010

118. Izadnegahdar R, Fox MP, Jeena P, Qazi SA, Thea DM. Revisiting pneumonia and exposure status in infants born to HIV-infected mothers. Pediatric Infect Dis J. (2014) 33:70-2. doi: 10.1097/INF.0b013e31829f0ade

119. Thorne PS, Kulhánková K, Yin M, Cohn R, Arbes SJ Jr, Zeldin DC. Endotoxin exposure is a risk factor for asthma: the national survey of endotoxin in United States housing. Am J Respir Crit Care Med. (2005) 172:13717. doi: $10.1164 / \mathrm{rccm} .200505-7580 \mathrm{C}$

120. Braun-Fahrländer C, Riedler J, Herz U, Eder W, Waser M, Grize L, et al. Environmental exposure to endotoxin and its relation to asthma in schoolage children. N Engl J Med. (2002) 347:869-77. doi: 10.1056/NEJMoa020057

121. Inagawa $\mathrm{H}$, Kohchi $\mathrm{C}$, Soma G-I. Oral administration of lipopolysaccharides for the prevention of various diseases: benefit and usefulness. Anticancer Res. (2011) 31:2431-6.

122. Stein MM, Hrusch CL, Gozdz J, Igartua C, Pivniouk V, Murray SE, et al. Innate immunity and asthma risk in amish and hutterite farm children. $N$ Engl J Med. (2016) 375:411-21. doi: 10.1056/NEJMoa1508749 
123. Ehrenstein V, Mutius V, Kries V. Reduced risk of hay fever and asthma among children of farmers. Clin Exp Allergy. (2000) 30:18793. doi: 10.1046/j.1365-2222.2000.00801.x

124. Leynaert B, Neukirch C, Jarvis D, Chinn S, Burney P, Neukirch F. Does living on a farm during childhood protect against asthma, allergic rhinitis, and atopy in adulthood? Am J Respir Crit Care Med. (2001) 164:182934. doi: 10.1164/ajrccm.164.10.2103137

125. Klintberg B, Berglund N, Lilja G, Wickman M, van Hage-Hamsten M. Fewer allergic respiratory disorders among farmers' children in a closed birth cohort from Sweden. Euro Respir J. (2001) 17:1151. doi: 10.1183/09031936.01.00027301

126. Strachan DP. Hay fever, hygiene, household size. BMJ. (1989) 299:1259. doi: 10.1136/bmj.299.6710.1259

127. Yazdanbakhsh M, Kremsner PG, van Ree R. Allergy, parasites, and the hygiene hypothesis. Science. (2002) 296:4904. doi: $10.1126 /$ science. 296.5567 .490

128. Wilson RH, Whitehead GS, Nakano H, Free ME, Kolls JK, Cook DN. Allergic sensitization through the airway primes Th17-dependent neutrophilia and airway hyperresponsiveness. Am J Respir Crit Care Med. (2009) 180:72030. doi: 10.1164/rccm.200904-0573OC

129. Scudellari M. News feature: cleaning up the hygiene hypothesis. Proc Natl Acad Sci USA. (2017) 114:1433-6. doi: 10.1073/pnas.1700688114

130. Platts-Mills TAE, Erwin E, Heymann P, Woodfolk J. Is the hygiene hypothesis still a viable explanation for the increased prevalence of asthma? Allergy. (2005) 60:25-31. doi: 10.1111/j.1398-9995.2005.00854.x

131. Litonjua AA, Milton DK, Celedon JC, Ryan L, Weiss ST, Gold DR. A longitudinal analysis of wheezing in young children: the independent effects of early life exposure to house dust endotoxin, allergens, and pets. J Allergy Clin Immunol. (2002) 110:736-42. doi: 10.1067/mai.2002.128948

132. Michel O, Kips J, Duchateau J, Vertongen F, Robert L, Collet H, et al. Severity of asthma is related to endotoxin in house dust. Am J Respir Crit Care Med. (1996) 154:1641-6. doi: 10.1164/ajrccm.154.6.8970348

133. Nightingale JA, Rogers DF, Hart LA, Kharitonov SA, Chung KF, Barnes PJ. Effect of inhaled endotoxin on induced sputum in normal, atopic, and atopic asthmatic subjects. Thorax. (1998) 53:563-71. doi: 10.1136/thx.53.7.563

134. Heumann D, Roger T. Initial responses to endotoxins and Gram-negative bacteria. Clinica Chimica Acta. (2002) 323:5972. doi: 10.1016/S0009-8981(02)00180-8

135. Park B, Song D, Kim H, Choi B-S, Lee H, Lee J-O. The structural basis of LPS recognition by the TLR4-MD-2 complex. Nature. (2009) 458:11915. doi: 10.1038/nature07830

136. Rylander R, Bake B, Fischer JJ, Helander IM. Pulmonary function and symptoms after inhalation of endotoxin. Am Rev Respir Dis. (1989) 140:9816. doi: 10.1164/ajrccm/140.4.981

137. Michel O, Nagy AM, Schroeven M, Duchateau J, Nève J, Fondu P, et al. Doseresponse relationship to inhaled endotoxin in normal subjects. Am J Respir Crit Care Med. (1997) 156:1157-64. doi: 10.1164/ajrccm.156.4.97-02002

138. Williams LK, Ownby DR, Maliarik MJ, Johnson CC. The role of endotoxin and its receptors in allergic disease. Ann Allergy Asthma Immunol. (2005) 94:323-32. doi: 10.1016/S1081-1206(10)60983-0

139. Hayashi F, Smith KD, Ozinsky A, Hawn TR, Yi EC, Goodlett DR, et al. The innate immune response to bacterial flagellin is mediated by Toll-like receptor 5. Nature. (2001) 410:1099-103. doi: 10.1038/35074106

140. Steiner TS, Nataro JP, Poteet-Smith CE, Smith JA, Guerrant RL. Enteroaggregative Escherichia coli expresses a novel flagellin that causes IL-8 release from intestinal epithelial cells. J Clin Invest. (2000) 105:176977. doi: 10.1172/JCI8892

141. Eaves-Pyles T, Murthy K, Liaudet L, Virág L, Ross G, Soriano FG, et al. Flagellin, a novel mediator of Salmonella-induced epithelial activation and systemic inflammation: I kappa $B$ alpha degradation, induction of nitric oxide synthase, induction of proinflammatory mediators, cardiovascular dysfunction. J Immunol. (2001) 166:1248-60. doi: 10.4049/jimmunol.166.2.1248

142. Hajam IA, Dar PA, Shahnawaz I, Jaume JC, Lee JH. Bacterial flagellin-a potent immunomodulatory agent. Exp Mol Med. (2017) 49:e373. doi: 10.1038/emm.2017.172

143. Shim JU, Lee SE, Hwang W, Lee C, Park JW, Sohn JH, et al. Flagellin suppresses experimental asthma by generating regulatory dendritic cells and $\mathrm{T}$ cells. J Allergy Clin Immunol. (2016) 137:426-35. doi: 10.1016/j.jaci.2015.07.010

144. Roduit C, Wohlgensinger J, Frei R, Bitter S, Bieli C, Loeliger S, et al. Prenatal animal contact and gene expression of innate immunity receptors at birth are associated with atopic dermatitis. J Allergy Clin Immunol. (2011) 127:179-85:185.e1. doi: 10.1016/j.jaci.2010.10.010

145. Luoma R, Koivikko A, Viander M. Development of asthma, allergic rhinitis and atopic dermatitis by the age of five years. A prospective study of 543 newborns. Allergy. (1983) 38:339-46. doi: 10.1111/j.1398-9995.1983.tb04128.x

146. Wilson RH, Maruoka S, Whitehead GS, Foley JF, Flake GP, Sever ML, et al. The Toll-like receptor 5 ligand flagellin promotes asthma by priming allergic responses to indoor allergens. Nat Med. (2012) 18:170510. doi: $10.1038 / \mathrm{nm} .2920$

147. Nagayama Y, Tsubaki T, Toba T, Kawakami H, Okusu K. Role of bacterial infection in the exacerbation of acute or prolonged asthma attack in children. Allergology Int. (1999) 48:137-44. doi: 10.1046/j.1440-1592.1999.00128.x

148. Hilty M, Burke C, Pedro H, Cardenas P, Bush A, Bossley C, et al. Disordered microbial communities in asthmatic airways. PLoS ONE. (2010) 5:e8578. doi: 10.1371/journal.pone.0008578

149. Peng X, Wu Y, Kong X, Chen Y, Tian Y, Li Q, et al. Neonatal streptococcus pneumoniae pneumonia induces an aberrant airway smooth muscle phenotype and AHR in mice model. BioMed Res Int. (2019) 2019:1948519. doi: 10.1155/2019/1948519

150. Marangu D, Zar HJ. Childhood pneumonia in low-and-middleincome countries: an update. Paediatr Respir Rev. (2019) 32:3-9. doi: 10.1016/j.prrv.2019.06.001

151. Izadnegahdar R, Cohen AL, Klugman KP, Qazi SA. Childhood pneumonia in developing countries. Lancet Respir Med. (2013) 1:574-84. doi: 10.1016/S2213-2600(13)70075-4

152. Otero C, Paz RD, Galassi N, Bezrodnik L, Finiasz MR, Fink S. Immune response to $\mathrm{S}$ treptococcus pneumoniae in asthma patients: comparison between stable situation and exacerbation. Clin Exp Immunol. (2013) 173:92-101. doi: $10.1111 /$ cei.12082

153. Tan TQ. Pediatric invasive pneumococcal disease in the United States in the era of pneumococcal conjugate vaccines. Clin Microbiol Rev. (2012) 25:409-19. doi: 10.1128/CMR.00018-12

154. de Benedictis FM, Kerem E, Chang AB, Colin AA, Zar HJ, Bush A. Complicated pneumonia in children. Lancet. (2020) 396:786-98. doi: 10.1016/S0140-6736(20)31550-6

155. Zampoli M, Kappos A, Wolter N, von Gottberg A, Verwey C, Mamathuba R, et al. Etiology and incidence of pleural empyema in South African children. Pediatric Infect Dis J. (2015) 34:1305-10. doi: 10.1097/INF.0000000000000880

156. Olarte L, Barson WJ, Barson RM, Romero JR, Bradley JS, Tan TQ, et al. Pneumococcal pneumonia requiring hospitalization in US children in the 13-valent pneumococcal conjugate vaccine era. Clin Infect Dis. (2017) 64:1699-704. doi: 10.1093/cid/cix115

157. Bisgaard H, Hermansen MN, Bønnelykke K, Stokholm J, Baty F, Skytt NL, et al. Association of bacteria and viruses with wheezy episodes in young children: prospective birth cohort study. BMJ. (2010) 341:c4978. doi: 10.1136/bmj.c4978

158. Bisgaard H, Hermansen MN, Buchvald F, Loland L, Halkjaer LB, Bønnelykke $\mathrm{K}$, et al. Childhood asthma after bacterial colonization of the airway in neonates. N Engl J Med. (2007) 357:1487-95. doi: 10.1056/NEJMoa052632

159. Kama Y, Kato M, Yamada Y, Koike T, Suzuki K, Enseki M, et al. The suppressive role of Streptococcus pneumoniae colonization in acute exacerbations of childhood bronchial asthma. Int Arch Allergy Immunol. (2020) 181:191-9. doi: 10.1159/000504541

160. Preston JA, Essilfie A-T, Horvat JC, Wade MA, Beagley KW, Gibson PG, et al. Inhibition of allergic airways disease by immunomodulatory therapy with whole killed Streptococcus pneumoniae. Vaccine. (2007) 25:815462. doi: 10.1016/j.vaccine.2007.09.034

161. Schuller DE. Prophylaxis of otitis media in asthmatic children. Pediatr Infect Dis. (1983) 2:280-3. doi: 10.1097/00006454-198307000-00004

162. Agrawal A, Murphy TF. Haemophilus influenzae infections in the $H$. influenzae type b conjugate vaccine era. J Clin Microbiol. (2011) 49:372832. doi: 10.1128/JCM.05476-11 
163. Langereis JD, de Jonge MI. Invasive disease caused by nontypeable Haemophilus influenzae. Emerg Infect Dis. (2015) 21:1711-8. doi: 10.3201/eid2110.150004

164. Avadhanula V, Rodriguez CA, Ulett GC, Bakaletz LO, Adderson EE. Nontypeable Haemophilus influenzae adheres to intercellular adhesion molecule 1 (ICAM-1) on respiratory epithelial cells and upregulates ICAM-1 expression. Infect Immun. (2006) 74:830-8. doi: 10.1128/IAI.74.2.830-838.2006

165. Howard AJ, Dunkin KT, Millar GW. Nasopharyngeal carriage and antibiotic resistance of Haemophilus influenzae in healthy children. Epidemiol Infect. (1988) 100:193-203. doi: 10.1017/S0950268800067327

166. Simpson JL, Daly J, Baines KJ, Yang IA, Upham JW, Reynolds PN, et al. Airway dysbiosis: Haemophilus influenzae and Tropheryma in poorly controlled asthma. Euro Respir J. (2016) 47:792. doi: 10.1183/13993003.00405-2015

167. Wood LG, Simpson JL, Hansbro PM, Gibson PG. Potentially pathogenic bacteria cultured from the sputum of stable asthmatics are associated with increased 8-isoprostane and airway neutrophilia. Free Radic Res. (2010) 44:146-54. doi: 10.3109/10715760903362576

168. Essilfie A-T, Simpson JL, Horvat JC, Preston JA, Dunkley ML, Foster PS, et al. Haemophilus influenzae infection drives IL-17mediated neutrophilic allergic airways disease. PLoS Pathog. (2011) 7:e1002244. doi: 10.1371/journal.ppat.1002244

169. Yang X, Wang Y, Zhao S, Wang R, Wang C. Long-term exposure to low-dose Haemophilus influenzae during allergic airway disease drives a steroid-resistant neutrophilic inflammation and promotes airway remodeling. Oncotarget. (2018) 9:24898-913. doi: 10.18632/oncotarget. 24653

170. Berg G, Rybakova D, Fischer D, Cernava T, M.-Vergès CC, Charles $\mathrm{T}$, et al. Microbiome definition re-visited: old concepts and new challenges. Microbiome. (2020) 8:1-22. doi: 10.1186/s40168-02000875-0

171. Gollwitzer ES, Saglani S, Trompette A, Yadava K, Sherburn R, McCoy KD, et al. Lung microbiota promotes tolerance to allergens in neonates via PD-L1. Nat Med. (2014) 20:642-7. doi: 10.1038/nm.3568

172. Lewkowich IP, Herman NS, Schleifer KW, Dance MP, Chen BL, Dienger $\mathrm{KM}$, et al. $\mathrm{CD} 4+\mathrm{CD} 25+\mathrm{T}$ cells protect against experimentally induced asthma and alter pulmonary dendritic cell phenotype and function. J Exp Med. (2005) 202:1549-61. doi: 10.1084/jem.200 51506

173. Hartl D, Koller B, Mehlhorn AT, Reinhardt D, Nicolai T, Schendel DJ, et al. Quantitative and functional impairment of pulmonary CD4+ CD25hi regulatory $\mathrm{T}$ cells in pediatric asthma. J Allergy Clin Immunol. (2007) 119:1258-66. doi: 10.1016/j.jaci.2007.02.023

174. Baatjes A, Smith S, Watson R, Howie K, Murphy D, Larché M, et al. $\mathrm{T}$ regulatory cell phenotypes in peripheral blood and bronchoalveolar lavage from non-asthmatic and asthmatic subjects. Clin Exp Allergy. (2015) 45:1654-62. doi: 10.1111/cea.12594

175. Pattaroni C, Watzenboeck ML, Schneidegger S, Kieser S, Wong NC, Bernasconi E, et al. Early-life formation of the microbial and immunological environment of the human airways. Cell Host Microbe. (2018) 24:857-65 e4. doi: 10.1016/j.chom.2018.10.019

176. Patrick DM, Sbihi H, Dai DLY, Al Mamun A, Rasali D, Rose C, et al. Decreasing antibiotic use, the gut microbiota, and asthma incidence in children: evidence from population-based and prospective cohort studies. Lancet Respir Med. (2020) 8:1094-105. doi: 10.1016/S2213-2600(20) 30052-7

177. Bosch AATM, Levin E, van Houten MA, Hasrat R, Kalkman G, Biesbroek G, et al. Development of upper respiratory tract microbiota in infancy is affected by mode of delivery. EBioMedicine. (2016) 9:33645. doi: 10.1016/j.ebiom.2016.05.031

178. Wypych TP, Marsland BJ. Antibiotics as instigators of microbial dysbiosis: implications for asthma and allergy. Trends Immunol. (2018) 39:697711. doi: 10.1016/j.it.2018.02.008

179. Taylor SL, Leong LEX, Choo JM, Wesselingh S, Yang IA, Upham JW, et al. Inflammatory phenotypes in patients with severe asthma are associated with distinct airway microbiology. J Allergy Clin Immunol. (2018) 141:94103.e15. doi: 10.1016/j.jaci.2017.03.044
180. Ahmadizar F, Vijverberg SJH, Arets HGM, de Boer A, Turner S, Devereux G, et al. Early life antibiotic use and the risk of asthma and asthma exacerbations in children. Pediatr Allergy Immunol. (2017) 28:4307. doi: $10.1111 /$ pai. 12725

181. Ni J, Friedman H, Boyd BC, McGurn A, Babinski P, Markossian T, et al. Early antibiotic exposure and development of asthma and allergic rhinitis in childhood. BMC Pediatrics. (2019) 19:225. doi: 10.1186/s12887-0191594-4

182. Stacy A, Andrade-Oliveira V, McCulloch JA, Hild B, Oh JH, PerezChaparro PJ, et al. Infection trains the host for microbiota-enhanced resistance to pathogens. Cell. (2021) 184:615-27.e17. doi: 10.1016/j.cell.2020. 12.011

183. Wypych TP, Pattaroni C, Perdijk O, Yap C, Trompette A, Anderson D, et al. Microbial metabolism of l-tyrosine protects against allergic airway inflammation. Nat Immunol. (2021) 22:279-86. doi: 10.1038/s41590-020-00856-3

184. Hamada K, Goldsmith CA, Goldman A, Kobzik L. Resistance of very young mice to inhaled allergen sensitization is overcome by coexposure to an air-pollutant aerosol. Am J Respir Crit Care Med. (2000) 161:128593. doi: 10.1164/ajrccm.161.4.9906137

185. Ohki Y, Tokuyama K, Mayuzumi H, Sato A, Koyama H, Takizawa T, et al. Characteristic features of allergic airway inflammation in a murine model of infantile asthma. Int Arch Allergy Immunol. (2005) 138:518. doi: $10.1159 / 000087357$

186. Carnieli DS, Yoshioka E, Silva LF, Lanças T, Arantes FM, Perini A, et al. Inflammation and remodeling in infantile, juvenile, and adult allergic sensitized mice. Pediatr Pulmonol. (2011) 46:650-65. doi: 10.1002/ppul.21436

187. Zuberi A, Lutz C. Mouse models for drug discovery. Can new tools and technology improve translational power? ILAR J. (2016) 57:17885. doi: 10.1093/ilar/ilw021

188. Saglani S, Mathie SA, Gregory LG, Bell MJ, Bush A, Lloyd CM. Pathophysiological features of asthma develop in parallel in house dust mite-exposed neonatal mice. Am J Respir Cell Mol Biol. (2009) 41:2819. doi: $10.1165 / \mathrm{rcmb} .2008-0396 \mathrm{OC}$

189. Bachus H, Kaur K, Papillion AM, Marquez-Lago TT, Yu Z, BallesterosTato A, et al. Impaired tumor-necrosis-factor-alpha-driven dendritic cell activation limits lipopolysaccharide-induced protection from allergic inflammation in infants. Immunity. (2019) 50:225-40 e4. doi: 10.1016/j.immuni.2018.11.012

190. Saglani S, Lui S, Ullmann N, Campbell GA, Sherburn RT, Mathie SA, et al. IL-33 promotes airway remodeling in pediatric patients with severe steroid-resistant asthma. J Allergy Clin Immunol. (2013) 132:67685.e13. doi: 10.1016/j.jaci.2013.04.012

191. Castanhinha S, Sherburn R, Walker S, Gupta A, Bossley CJ, Buckley J, et al. Pediatric severe asthma with fungal sensitization is mediated by steroid-resistant IL-33. J Allergy Clin Immunol. (2015) 136:31222.e7. doi: 10.1016/j.jaci.2015.01.016

192. Snelgrove RJ, Gregory LG, Peiró T, Akthar S, Campbell GA, Walker $\mathrm{SA}$, et al. Alternaria-derived serine protease activity drives IL-33mediated asthma exacerbations. J Allergy Clin Immunol. (2014) 134:58392.e6. doi: 10.1016/j.jaci.2014.02.002

193. Branchett WJ, Cook J, Oliver RA, Bruno N, Walker SA, St?lting H, et al. Airway macrophage-intrinsic TGF- $\beta 1$ regulates pulmonary immunity during early life allergen exposure. J Allergy Clin Immunol. (2021) 147:1892906. doi: 10.1016/j.jaci.2021.01.026

194. Tulic MK, Andrews D, Crook ML, Charles A, Tourigny MR, Moqbel R, et al. Changes in thymic regulatory T-cell maturation from birth to puberty: differences in atopic children. J Allergy Clin Immunol. (2012) 129:199-206.e4. doi: 10.1016/j.jaci.2011. 10.016

195. Al Nabhani Z, Dulauroy S, Marques R, Cousu C, Al Bounny $\mathrm{S}$, Déjardin $\mathrm{F}$, et al. A weaning reaction to microbiota is required for resistance to immunopathologies in the adult. Immunity. (2019) 50:1276-88.e5. doi: 10.1016/j.immuni.2019. 02.014

196. Poole A, Urbanek C, Eng C, Schageman J, Jacobson S, O'Connor BP, et al. Dissecting childhood asthma with nasal 
transcriptomics distinguishes subphenotypes of disease. I Allergy Clin Immunol. (2014) 133:670-8.e12. doi: 10.1016/j.jaci.2013. 11.025

Conflict of Interest: The authors declare that the research was conducted in the absence of any commercial or financial relationships that could be construed as a potential conflict of interest.
Copyright $\odot 2021$ Mthembu, Ikwegbue, Brombacher and Hadebe. This is an openaccess article distributed under the terms of the Creative Commons Attribution License (CC BY). The use, distribution or reproduction in other forums is permitted, provided the original author(s) and the copyright owner(s) are credited and that the original publication in this journal is cited, in accordance with accepted academic practice. No use, distribution or reproduction is permitted which does not comply with these terms. 